\title{
A multidisciplinary approach to assess the health state of heritage structures: The case study of the Church of Monastery of Jerónimos in Lisbon
}

\author{
Maria-Giovanna Masciotta ${ }^{a, *}$, João C.A. Roque ${ }^{b}$, Luís F. Ramos ${ }^{a}$, Paulo B. Lourenço ${ }^{a}$ \\ a ISISE, University of Minho, Department of Civil Engineering, Campus de Azurém, Guimarães, Portugal \\ ${ }^{\mathrm{b}}$ Polytechnic Institute of Bragança, Department of Applied Mechanics, Bragança, Portugal
}

\section{H I G H L I G H T S}

- A wide experimental/numerical campaign is carried out on a famous historic church.

- The structural behaviour is evaluated through a multidisciplinary approach.

- Different diagnosis and analysis tools are used for assessing the system health.

- Potential collapse mechanisms are identified.

- The environmental variability of static and dynamic behaviour is analysed.

\section{A R T I C L E I N F O}

Article history:

Received 14 January 2016

Received in revised form 22 April 2016

Accepted 28 April 2016

Available online 4 May 2016

\section{Keywords:}

Historical masonry structures

Multidisciplinary approach

Structural health monitoring

Environmental effects

Safety assessment

\begin{abstract}
A B S T R A C T
The preservation and risk mitigation of built cultural heritage require the use of reliable tools which enable to give a better insight into the complex behaviour of these structures, by providing a correct diagnosis of their health conditions, and to identify potential vulnerabilities in order to prevent the risk of damage and to design in advance adequate retrofit solutions. The present paper describes an extensive experimental/numerical investigation campaign carried out on the Church of Monastery of Jerónimos in Lisbon in accordance with an iterative multidisciplinary approach and with the purpose of assessing the health state of one of the most prominent Portuguese monument, in light of future prevention actions. Special stress is given to the diagnostic procedure which includes and details in situ and laboratory testing, dynamic identification, continuous structural health monitoring and analysis of environmental effects on the static and dynamic behaviour of the church. The structural performance of the temple under conditions of gravity loading is analysed as well and potential collapse mechanisms are identified. The results are compared with the actual response of the temple allowing to evaluate its safety level.
\end{abstract}

(c) 2016 Elsevier Ltd. All rights reserved.

\section{Introduction}

Architectural heritage is an irreplaceable expression of the intellectual richness and cultural diversity of modern societies. The protection and enhancement of heritage structures do imply acknowledgement and respect of different cultural roots and belief systems. In a changing world, built cultural landmarks provide

\footnotetext{
* Corresponding author at: ISISE, University of Minho, Department of Civil Engineering, Campus de Azurém, 4800-058 Guimarães, Portugal.

E-mail addresses: mg.masciotta@gmail.com (M.-G. Masciotta),jroque@ipb.pt (J.C.A. Roque), lramos@civil.uminho.pt (L.F. Ramos), pbl@civil.uminho.pt (P.B. Lourenço).
}

identity to people, regions and towns and act as live documents of outstanding technical achievements from which study and utilization the mankind can still learn and improve. In addition to their historical interest, monuments do yield aesthetic, environmental and economic benefits, contributing to the global wealth and the touristic attractiveness of a country. For these reasons, the conservation and maintenance of architectural heritage is not only a cultural requirement [1].

In this context, the structural analysis and the safety assessment of historical constructions are issues of great importance, but they conceal several challenges and difficulties due to the geometrical complexity of ancient structures, the variability of 
materials and building techniques adopted, the poor knowledge on past events which might have affected the current condition of the constructions and the lack of design codes. Thus, the restoration projects related to architectural heritage are not straightforward and they require a multidisciplinary approach able to foster a fully comprehension of the structural behaviour before proceeding with specific conservation measures. In the last decades, recommendations have been proposed [3] to ensure systematic methods of analysis and adequate tools of intervention in order to guarantee safety and durability of heritage structures without compromising their historical value.

In the process of preserving ancient buildings, engineers should act according to a step-by-step methodology organised in stages similar to those used in medicine [2]: condition survey (anamnesis), identification of the causes triggering damage and decay (diagnosis), choice of the remedial measures (therapy) and control of the efficiency of the interventions (control). Within this methodology, the first two stages are crucial for the subsequent decision-making with regard to the need of specific treatment measures, whereas the last stage is fundamental in terms of monitoring and evaluation of the effectiveness of the intervention. Any heritage structure is the result of different building phases, constructional techniques and changes which have followed over time up to the present state. Therefore, condition survey, direct observation of structural and non-structural damage, historical investigation, non-destructive tests, health monitoring and structural analysis procedures are all indispensable tasks within this iterative process for safety evaluation of heritage structures. A more exhaustive discussion on these issues can be found, e.g. [4].

In this paper, an outstanding example of Portuguese architectural heritage, i.e. the Church of Monastery of Jerónimos in Lisbon, is selected as a case study in order to provide the reader with a fullscale application in which different diagnosis and analysis tools are combined together to achieve a thorough assessment of the structural performance of the monument in accordance with the aforementioned multidisciplinary approach. This case study may also serve as an example on how to address similar issues in analogous heritage structures. The information acquired at each stage represent a step forward within this gradual and continuous process of knowledge accumulation. Firstly, the paper details the investigations carried out for the experimental characterization of the church, including ultrasonic and radar inspections for the definition of the internal constitution of the structural elements, laboratory tests on sampled materials for the estimation of the mechanical features and output-only modal analysis techniques for the identification of the dynamic parameters of the structure. Then, two main aspects are treated: the safety assessment of the church under conditions of gravity loading and the characterization of the structural behaviour over time from both static and dynamic points of view. Special regard is given to the environmental variability of the system, as subtle changes caused by damage in masonry structures may be often masked by changes due to varying ambient conditions [5-6]. Indeed, in the last decades, the analysis of the environmental effects on the system's behaviour has been regularly introduced in the common practice of structural health monitoring [5-11].

Although the structural behaviour of this monument has been already explored [7,12], new and fundamental aspects are addressed in the present work. The final scope of the paper is to give completeness to the diagnostic investigation of the Church of Jerónimos, merging the findings hereafter presented with the ones obtained in previous studies, in order to attain a deep comprehension of the global behaviour of this outstanding historical landmark for future design of adequate remedial measures.

\section{Description of the case study and historical background}

Built in three successive phases during the XVI century, the Church of 'Santa Maria de Belém' is within one of the most notable examples of Late Gothic Manueline style of Portuguese architecture, namely the monastic complex of Jerónimos in Lisbon. The majestic monastery (Fig. 1a), four times smaller than the original planned construction, stretches over an area of $300 \times 50 \mathrm{~m}^{2}$ and develops around two courts. The larger court is bordered by a two-storey arcade which hosts the Ethnographic Museum of Archaeology and the Maritime Museum, whereas the smaller court or Cloister (Fig. 1c) is bordered by the Sacristy, the Chapter Room, the Refectory and the Church (Fig. 1b), object of the present work.

Oriented towards the liturgical East, the plan of the temple is characterized by a cruciform shape with a single nave crossed by a transept with two lateral chapels and a chancel (Fig. 2). A single bell tower of $50 \mathrm{~m}$ height rises in the corner between south and west façades. The church was built with limestone ("calcário de lioz") quarried locally and has considerable dimensions, viz. a length of $70 \mathrm{~m}$, a width of $23 \mathrm{~m}$ ( $40 \mathrm{~m}$ in the transept) and an average height of $24 \mathrm{~m}$. Either limb is covered with a slightly curved barrel vault provided with stone ribs that branch according to a spider's web pattern (Fig. 2 b and c). Exceptional examples of space unit of the latest Gothic, the barrel vaults spring directly from one external wall to the other. Two rows of octagonal columns with a free height of $16 \mathrm{~m}$ and a radius ranging from $1.04 \mathrm{~m}$ (nave columns) to $1.88 \mathrm{~m}$ (nave-transept columns) divide almost imperceptibly the longitudinal limb and the clear fusion of the naves. The columns are connected to the vault above by means of large fan capitals and do act as supports reducing the free span of the nave (Fig. 2c). On top of the vaults, brick masonry wallets built during the $1930 \mathrm{~s}$ provide support for the roofing tiles. The thickness of the walls varies from side to side ranging from $1.90 \mathrm{~m}$ of the south wall to $2.5-2.65 \mathrm{~m}$ of the east walls (chancel side), whereas the north wall has an average thickness of around $3.5 \mathrm{~m}$ due to the presence of an internal staircase which provides access to choir, cloister and bell tower. It is noticed that the south wall is pierced by large openings and its stability is ensured by three trapezoidal buttresses, which are indeed not aligned with the columns of the church. This proves that the south wall existed before the conception of the vault.

The seismic performance of the compound was successfully tested during the great earthquake of 1755 . In that occasion, no severe damage was registered in the monastery. On the contrary, the subsequent shake of 1756 caused the collapse of one of the column supporting the vaults of the church (with subsequent ruin of the nave) and also the partial collapse of the vault of the higher choir [12]. In addition to these events, during the XIX century, changes were made in the structure of the two towers and in the roof. The effect of these changes in the seismic performance of the structure remained an open issue [12]. Hence, several studies and numerical simulations have been performed in the last decades to investigate the structural behaviour of this temple [12-14].

\section{In situ investigations in the church}

\subsection{Non-destructive tests (NDTs)}

In order to assess the safety of the Church of Monastery of Jerónimos, several preliminary in situ investigations have been carried out aimed at gaining a thorough insight into the internal constitution and integrity of the structural elements, determining their actual geometry and identifying possible local defects and vulnerabilities. In detail, the NDTs experimental campaign focused on the 


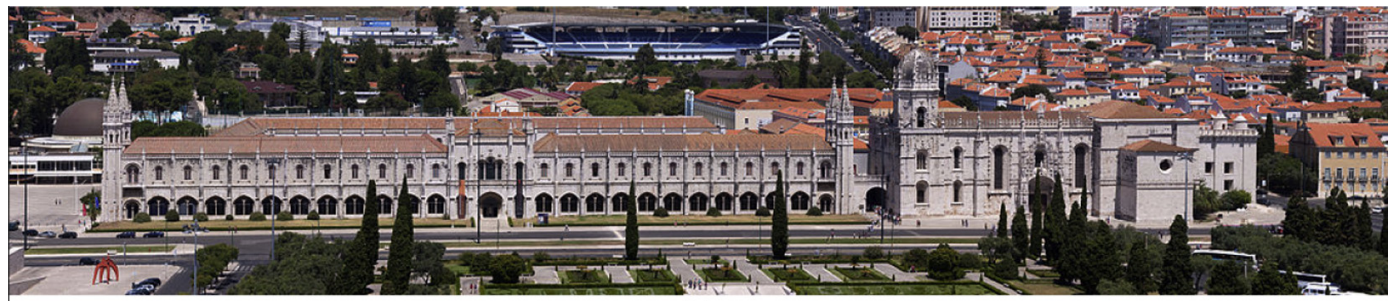

(a)

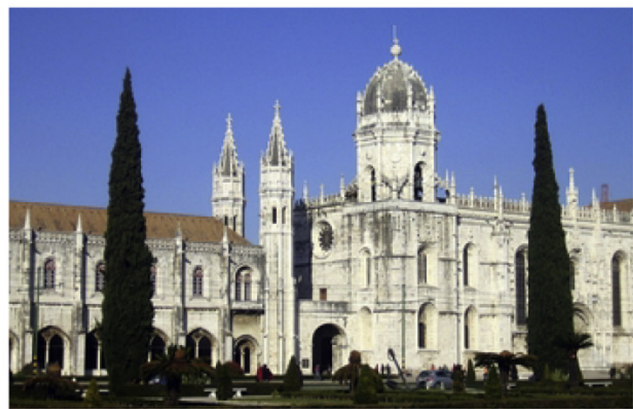

(b)

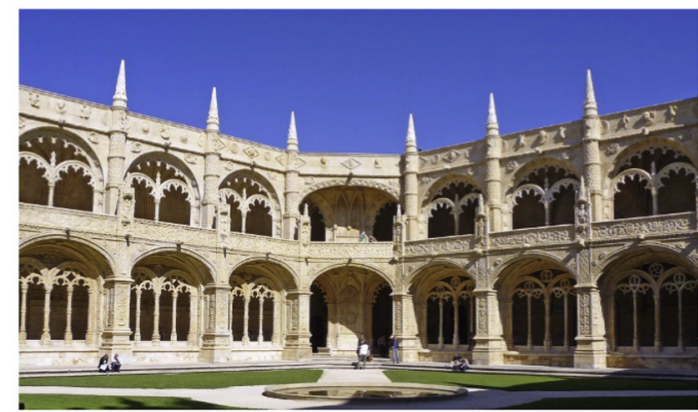

(c)

Fig. 1. Monastery of Jerónimos: (a) general view of the compound; (b) outer view of the Church; and (c) inner view of the Cloyster.

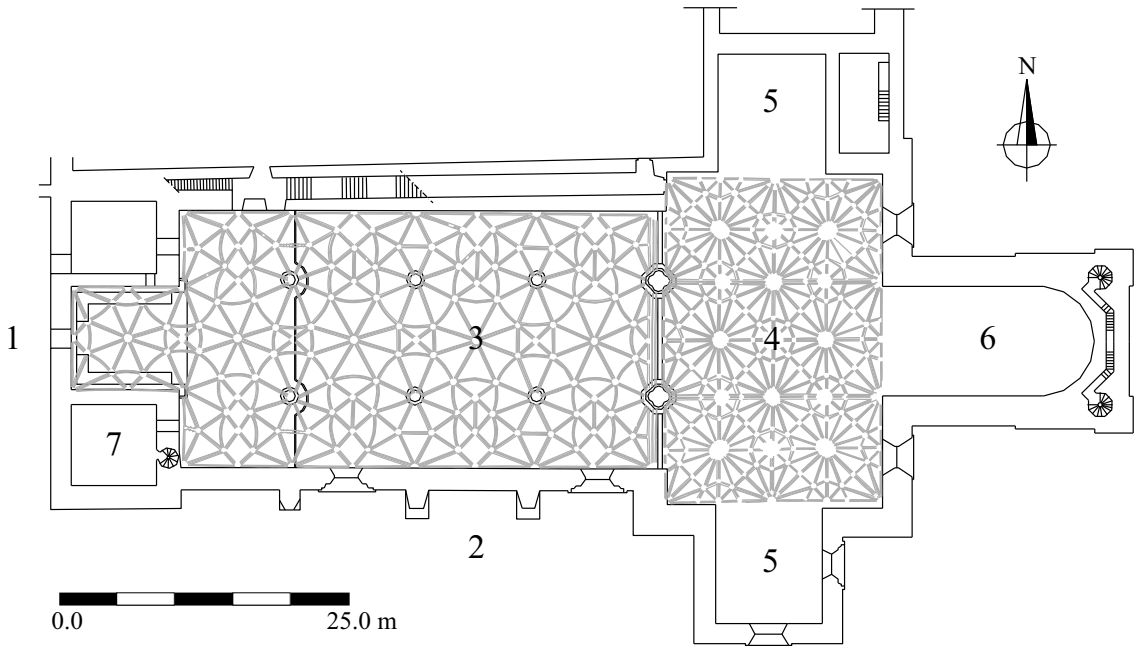

(a)

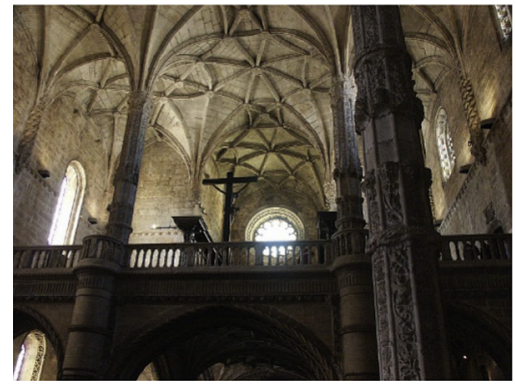

(b)

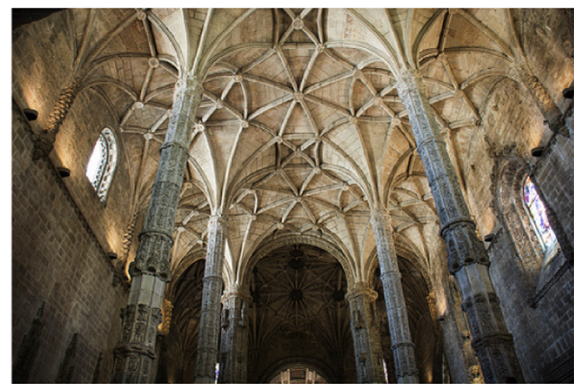

(c)

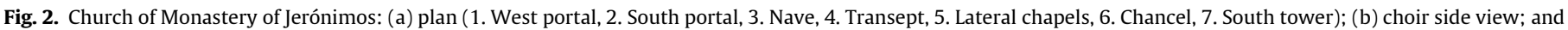
(c) detail of the ribbed vault.

vertical bearing system and the nave vault of church, whose role in the structural response was deemed fundamental.

The topographic and photogrammetric survey of the nave vault [15] allowed to detect two different rib profiles serving to the laying of the arch-stones, which are held by cramp irons and are placed in concentric way starting from the supports up to the vault (Fig. 3a). The survey also pointed out the presence of transversal deformations of nearly $6 \mathrm{~cm}$ in the sidewalls and 


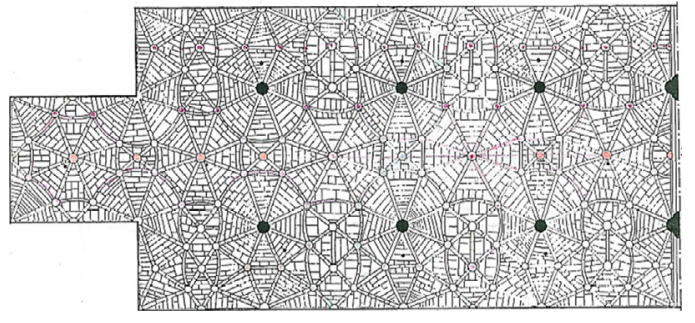

(a)

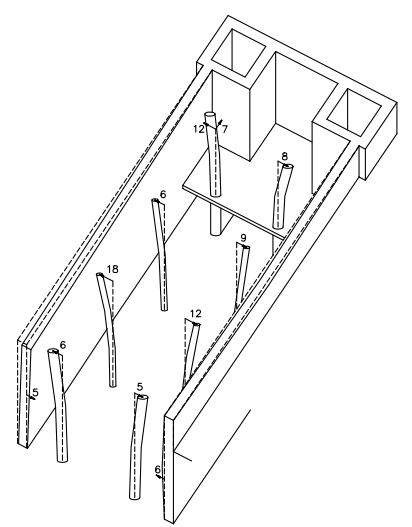

(b)

Fig. 3. In situ testing [15]: (a) topographic and photogrammetric survey of nave vault; and (b) out of plumbness of columns and sidewalls.

out-of-plumbness of the columns, which lean towards the longitudinal walls with deviations between $5 \mathrm{~cm}$ and $18 \mathrm{~cm}$ (Fig. $3 \mathrm{~b}$ ). Radar and boroscope investigations enabled to inspect the covering of the vault which is made of thin stone slabs of $8-10 \mathrm{~cm}$ thickness laying on the stone ribs and covered by a variable thickness mortar layer. The voids and encrustations found in this layer warned of the presence of cracks in the ribs. It is further noticed that the part of the slab inside the capitals is filled with a concrete-like material consisting of stones and clay mortar for a total thickness of $0.35-0.40 \mathrm{~m}$.

Results from the ultrasonic tests performed in three columns of the church highlighted that the columns of the nave are monolithic or formed by two/three limestone blocks with thin vertical joints, whereas the columns of the transept are made of four juxtaposed blocks [15]. Low speed values were obtained in two sections: at the base of the south column of the transept owing to the presence of fissures, and at $6.35 \mathrm{~m}$ height in one of the columns of the nave for undetected reasons. Complementary GPR investigations were also carried out in the four columns of the nave that feature larger slenderness. The inspections were executed at about $7 \mathrm{~m}$ height from the floor level (one third of the columns' development) and revealed the homogeneity of the material as well as the absence of significant anomalies and cramp irons between stone blocks. A few shallow cracks (or stone detachments) were found in the columns, likely imputable to high stress levels or material defects.

\subsection{Ambient vibration tests (AVTs) and dynamic identification}

Dynamic identification tests were conducted in the main nave between 20th and 21st of April 2005 [1,7,14,16] using ambient excitations as operational conditions. Before proceeding with the Ambient Vibration Tests (AVTs), a preliminary numerical modal analysis with a simplified FE model was carried out to select and optimize sensors number and layout, and to choose sampling frequency and time window for the data acquisition. According to the results, thirty measuring points were selected to acquire the dynamic response of the structure (Fig. 4a): twenty points were located either on top of the columns or on top of the nave extrados (after removing the tiles to avoid noise contamination from the roof structure above), whereas other ten points were deployed on top of the external walls of the nave so as to estimate the dynamic response of the church at the boundaries as well. Twenty-nine setups were used to record the accelerations of the chosen DOFs. Each setup consisted of two tri-axial force balanced accelerometers (Fig. 4b), namely one reference and one moving sensor, with a bandwidth range from DC to $100 \mathrm{~Hz}$, a dynamic range of $\pm 1.0 \mathrm{~g}$, a sensitivity of $10 \mathrm{~V} / \mathrm{g}$ and an operating temperature range from $-20^{\circ} \mathrm{C}$ to $70^{\circ} \mathrm{C}$. Each sensor was connected by cable to a strong motion recorder with 16-bit ADC analyser provided with batteries. The final resolution of both sensor and analyser was $8 \mu \mathrm{g}$. Note that the measurement equipment employed for the modal identification is the same used for the subsequent dynamic monitoring task.

In order to catch all meaningful vibration characteristics of the church, the signals were recorded with a sampling frequency of $200 \mathrm{~Hz}$ which is actually much higher than that required for the investigated structure, since the frequency content of the signals is below $20 \mathrm{~Hz}$. Moreover, considering that the length of the acquired time window should not be less than 1000-2000 times the structure's fundamental period [17], the modal identification was performed using time series of $600 \mathrm{~s}$ (10 min) which correspond to more than 2000 times the fundamental period of the church.

The extraction of the modal parameters from ambient data was carried out by comparing two different identification techniques, viz. the Enhanced Frequency Domain Decomposition (EFFD) [18] in the frequency domain and the data-driven Stochastic Subspace Identification (SSI) [19] in the time domain, both available in the commercial software ARTeMIS [20]. Either of the adopted identification technique allowed to estimate 8 vibration modes in the frequency range $3-16 \mathrm{~Hz}$. The results in terms of frequencies, damping ratios and MAC values are summarized in Table 1. Despite a good correlation between the frequencies identified by the two methods, the MAC points out a moderate correlation in terms of modes, except for the lower ones which show excellent correlation with values close to the unit. Stated that difficulties in extracting higher modes arise when dealing with low levels of excitation associated with ambient measurements, in the present case the poor correlation between mode shapes estimates is likely more imputable to the large number of different setups adopted for the AVTs rather than other factors. This explains why the correlation between damping ratios estimates also results not very good. However, in what concerns the first two vibration modes (Fig. 5), it is clear that the dynamic response of the church is dominated by the modal deflections of the columns. In detail, the first mode is a bending mode involving flexure in the transversal plane (northsouth direction), whereas the second mode is a local mode with significant components along both the vertical direction (nave vault) and the transversal direction (south longitudinal wall).

\subsection{Laboratory tests}

To gain more knowledge on the mechanical characteristics of the materials constituting the structural elements of the church, 


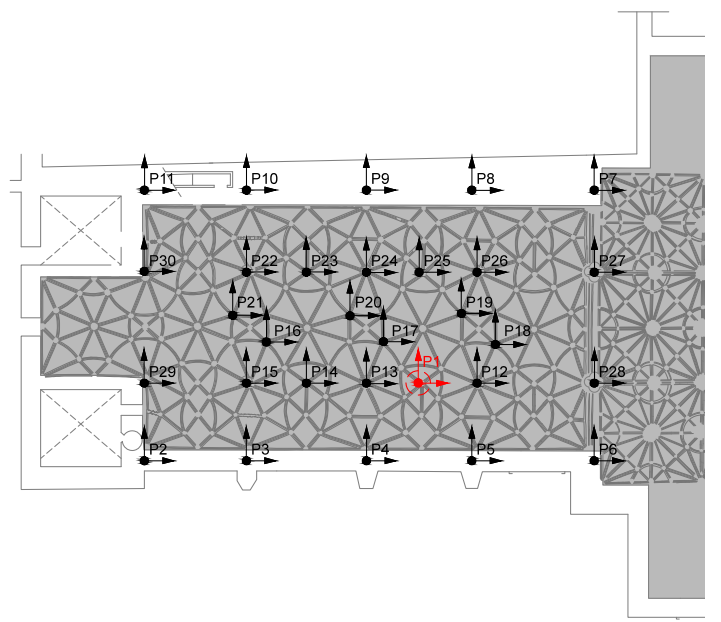

(a)

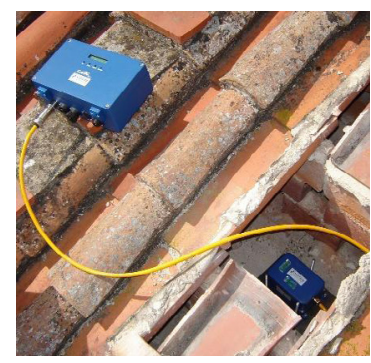

(b)

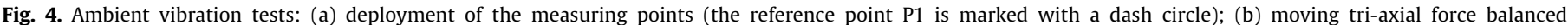
accelerometer used during the test.

Table 1

Comparison between the modal parameters estimated by the EFDD and the SSI.

\begin{tabular}{lrrllll}
\hline Mode shape & \multicolumn{2}{l}{$f[\mathrm{~Hz}]$} & & & $\xi \%]$ & \multirow{2}{*}{ MAC } \\
\cline { 2 - 3 } & EFDD & SSI & & EFDD & SSI & \\
\hline Mode 1 & 3.69 & 3.68 & 2.34 & 1.26 & 0.99 \\
Mode 2 & 5.12 & 5.04 & & 1.11 & 2.68 & 0.92 \\
Mode 3 & 6.29 & 6.30 & & 1.00 & 0.82 & 0.67 \\
Mode 4 & 7.23 & 7.29 & 0.77 & 1.44 & 0.67 \\
Mode 5 & 9.67 & 9.65 & 1.10 & 1.45 & 0.62 \\
Mode 6 & 11.64 & 11.65 & 1.20 & 1.46 & 0.36 \\
Mode 7 & 12.45 & 12.51 & 1.25 & 1.19 & 0.71 \\
Mode 8 & 14.99 & 15.09 & 1.31 & 2.77 & 0.49 \\
\hline
\end{tabular}

several laboratory tests were performed [16]. Given the historical value of the building and the consequent restrictions in the removal of specimens, the tests were carried out on ad hoc masonry specimens made of limestone with properties similar to the limestone used to build the church ("calcário de lioz"). The test campaign consisted of two types of uniaxial compressive tests, viz. monotonic tests and cyclic tests, conducted on both cylindrical specimens $\left(\varnothing 60 \times 120 \mathrm{~mm}^{3}\right)$ and masonry triplets $\left(120 \times 120 \times 180 \mathrm{~mm}^{3}\right.$ per unit), see Fig. 6 . All tests were carried out under conditions of constant humidity and temperature.

In the monotonic tests, an increasing load was applied to the specimens to identify a reference value for the ultimate strength and to gain insight into the stress-strain and post-peak behaviour of the material. The tests were performed displacement controlled $(\mathrm{v}=2 \mu \mathrm{m} / \mathrm{s}$ for the cylindrical samples and $\mathrm{v}=4 \mu \mathrm{m} / \mathrm{s}$ for the triplets) until failure and the force-displacement evolution was captured with LVDTs. In the cyclic tests, oscillating loads with values between $10 \%$ and $70 \%$ of the average compressive strength estimated through the monotonic tests were applied to the specimens. These tests were performed force controlled $(4 \mathrm{kN} / \mathrm{s})$, with the exception of the last loading cycle which was executed displacement controlled. In what concerns the masonry triplets, three prototypes were tested: triplet with smooth units and dry joints (SD);

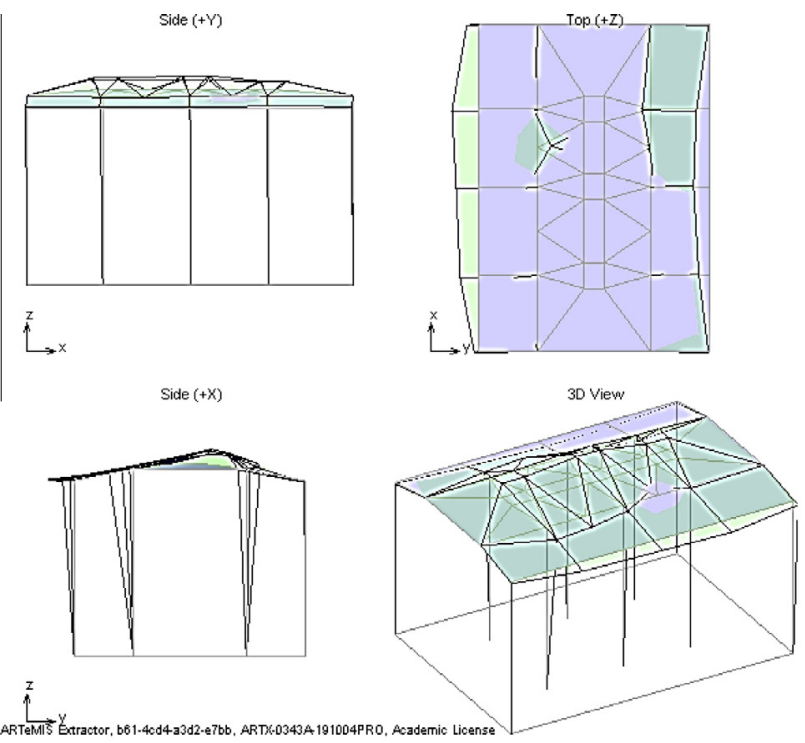

(a)

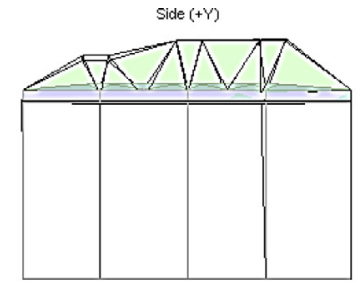

$\stackrel{z}{i} \rightarrow x$
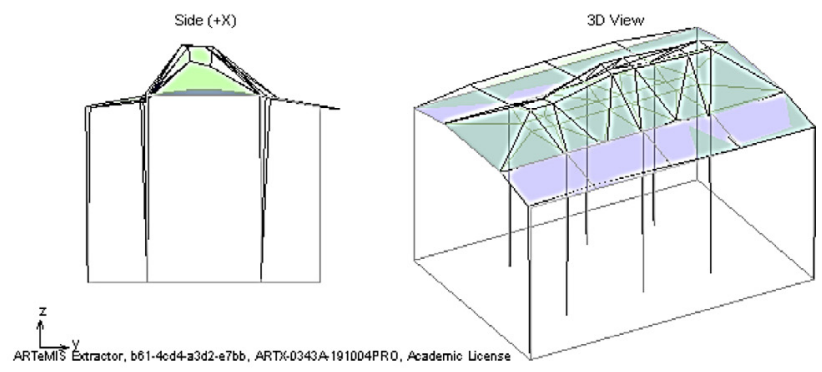

(b)

Fig. 5. Experimental mode shapes [7]: (a) first mode shape at $3.7 \mathrm{~Hz}$; and (b) second mode shape at $5.1 \mathrm{~Hz}$. 


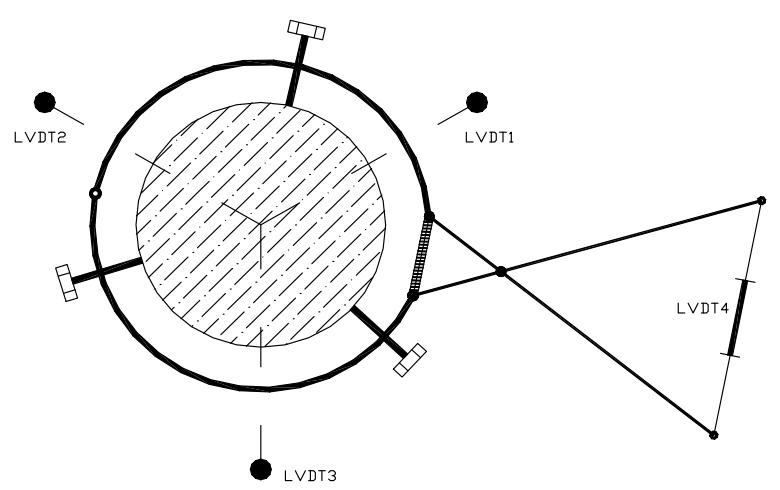

(a)

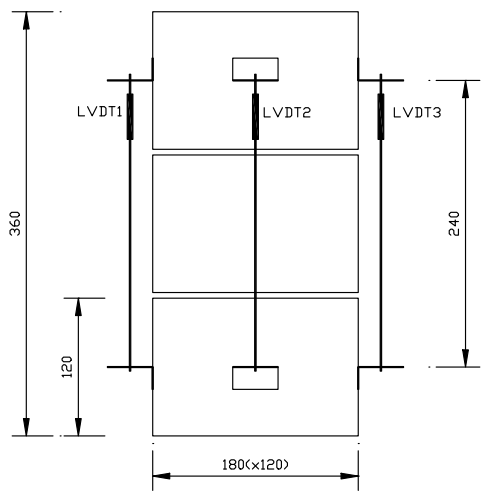

(c)

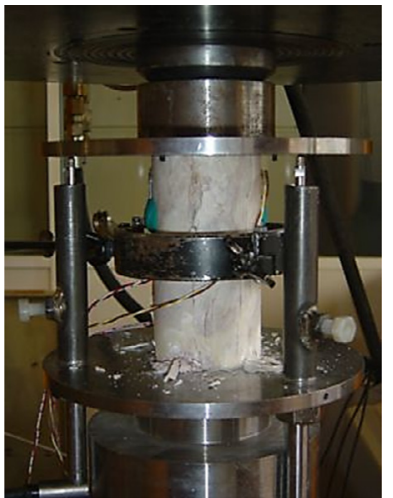

(b)

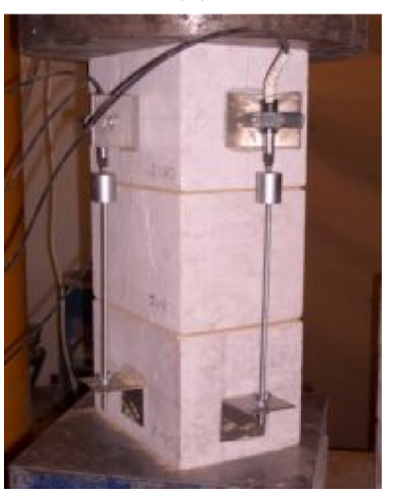

(d)

Fig. 6. Uniaxial compressive testing: LVDTs layout and test setup for (a and b) cylindrical specimens and (c and d) masonry triplets.

triplet with bush hammered units and dry joints (BD); and triplet with bush hammered units and sandy-clay joints (BC) of $5 \mathrm{~mm}$. Given the similarity with the historical masonry used in the construction of the church, the masonry prototype BC was finally selected as the most representative sample of the material used in the church. Table 2 summarizes the mechanical parameters obtained for both cylindrical specimens and BC masonry triplets in terms of compressive strength (fc), Young's modulus (E) and Poisson's ratio (v).

\section{Structural assessment}

After the historical analysis and the experimental investigations, the next stage of the procedure for the evaluation of the health state of the Church of Jerónimos focused on the assessment of the safety level of the building under conditions of constant gravity loads. To this end, a finite element analysis was carried out in DIANA [21] software. Given the size and the great complexity of the structure, the geometry of the finite element model was simplified to a great extent. Though, particular attention was paid in the discretization of the model in order to reproduce the geometrical stiffness of the church as close to reality as possible.

\subsection{Description of the FE model}

The 3D numerical model was built and calibrated using the dynamic features extracted from AVTs. The information provided by the NDTs was employed to accurately define the geometry of the FE model, whereas the results from the laboratory tests were used for the definition of the mechanical properties. The model consists of 2684 Timoshenko beam elements with quadratic interpolation, 4242 nodes and 25,452 degrees of freedom (Fig. 7). The supports are fully restrained, being rotations possible given the non-linear material behaviour assumed. Special attention is given to the modelling of the vault and the piers of the nave (Fig. 8a and $b$ ). In detail, the ribs profiles of the vault are modelled by beam elements with trapezoidal cross section, whereas a T cross-section is adopted for the rib-slab system. Given the marginal contribution to the structural response, the mortar layer covering the stone slabs is taken into account only in terms of equivalent mass. As far as the piers are concerned, the octagonal geometry of the shaft is approximated by beam elements having a circular cross-section (Fig. 8c). The capitals are represented at the base by elements with a cone-frustum geometry and in the transition part to the vault by cuneiform elements radially set out (Fig. 8d). The infill of the capitals is not modelled but in terms of mass, considering negligible its

Table 2

Mechanical parameters estimated from uniaxial compressive tests.

\begin{tabular}{|c|c|c|c|c|c|c|}
\hline \multirow[t]{2}{*}{ Sample } & \multicolumn{2}{|l|}{$\mathrm{f}_{\mathrm{c}}[\mathrm{MPa}]$} & \multicolumn{2}{|c|}{$\mathrm{E}_{30 \%-60 \%}[\mathrm{GPa}]$} & \multicolumn{2}{|l|}{$v$} \\
\hline & Monotonic & Cyclic & Monotonic & Cyclic & Monotonic & Cyclic \\
\hline Limestone cylindrical specimens & 102.1 & 99.8 & 50.2 & $50.0^{\mathrm{a}}$ & 0.25 & 0.25 \\
\hline Bush hammered \& clay joints masonry triplets (BC) & 58 & 61 & 25.9 & $53^{\mathrm{a}}$ & - & - \\
\hline
\end{tabular}

\footnotetext{
${ }^{a}$ Evaluated during the first loading/unloading cycle.
} 


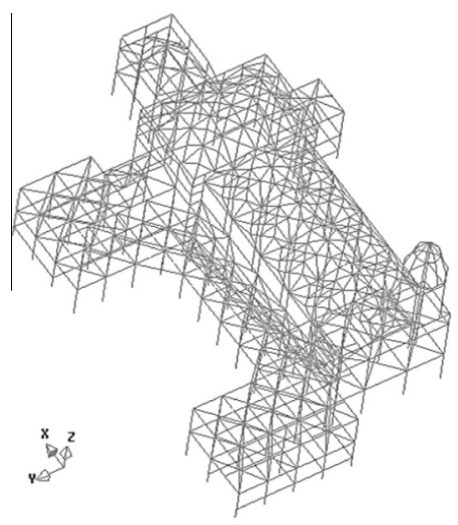

(a)

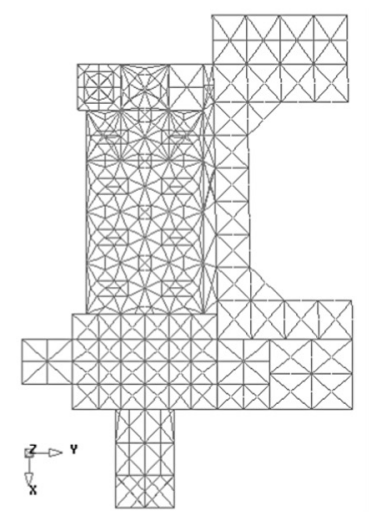

(b)

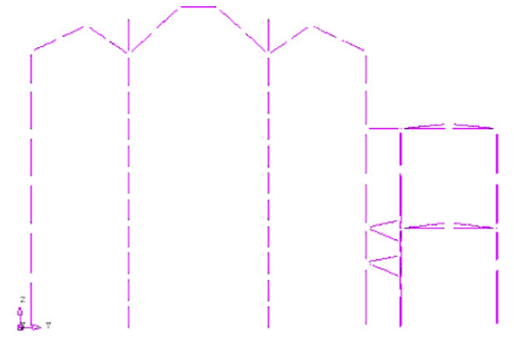

(c)

Fig. 7. FE model of the church: (a) perspective; (b) plan; (c) central arcade of the nave in transversal direction.

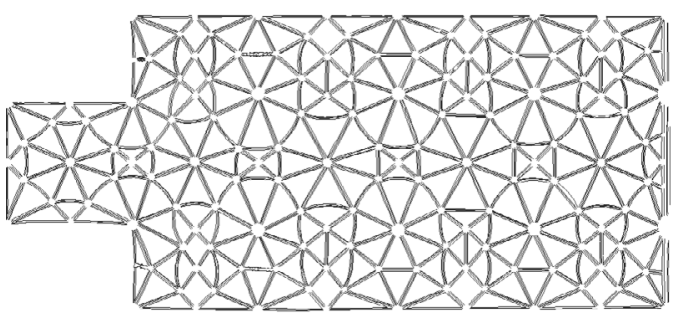

(a)
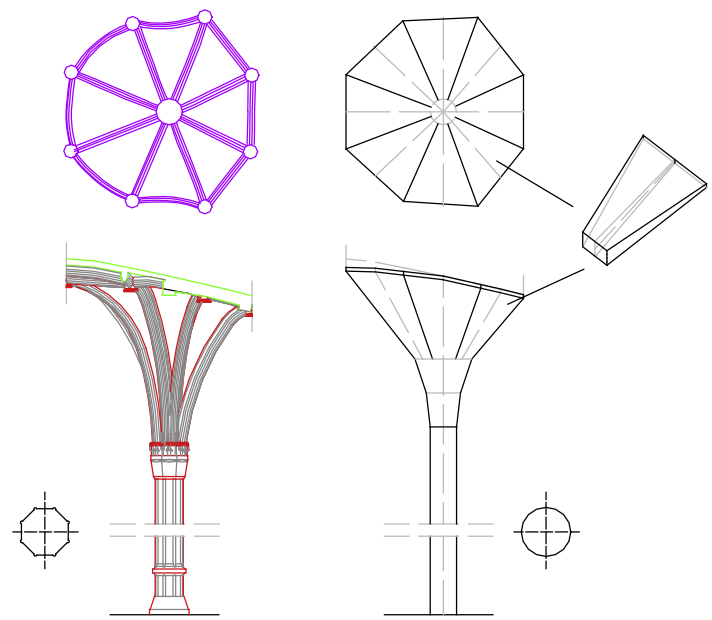

(c)

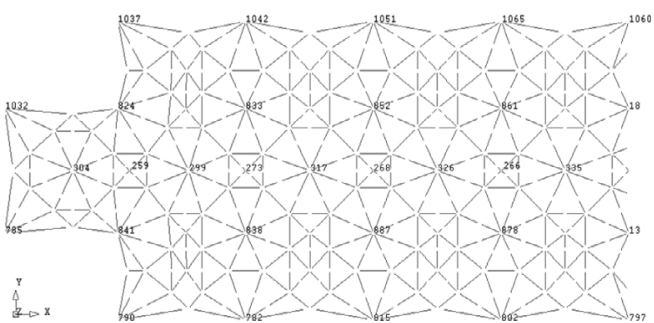

(b)

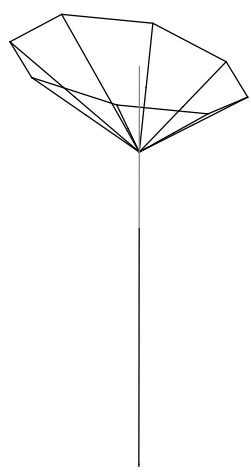

(d)

Fig. 8. Numerical modelling: (a) existing and (b) approximated configuration of the nave vault; (c) existing and (d) approximated configuration of the columns.

contribution to the structural response because of the poor mechanical properties of the material. The walls are modelled by a net of vertical and horizontal beam elements, with the mass entirely assigned to the vertical ones in order to avoid the occurrence of marginal flexural stresses due to gravity load in the horizontal elements.

The constitutive model adopted for the stone masonry is a total crack strain model [21] characterized by a parabolic stress-strain relationship with a compressive strength $f_{c d}=10 \mathrm{MPa}$ (estimated from the reference value obtained experimentally by taking into consideration the dispersion of the results, $\mathrm{CV} \approx 0.30 \%$, and a safety factor for ancient masonry equal to 3 ), a tensile strength $f_{t}=0.01 \mathrm{MPa}$ and a fracture energy $G_{c}=16 \mathrm{~kJ} / \mathrm{m}^{2}$. The material is assumed to be homogeneous with initial values of $25.9 \mathrm{GPa}$ for the Young's modulus and of 0.2 for the Poisson's ratio. The weight per unit volume adopted for the masonry is $24 \mathrm{kN} / \mathrm{m}^{3}$. A comprehensive description of the FE model and its mechanical features is found elsewhere, e.g. [16].

A modal analysis was then carried out prior to the calibration of the numerical model. Table 3 presents the numerical and experimental eigenfrequencies identified for comparable modes. Owing to the complexity of the structure and the difficulties in the modal parameters estimation, the FE model was manually tuned to the dynamic experimental results by using as a reference value for 
Table 3

Comparison between experimental and numerical eigenfrequencies.

\begin{tabular}{lllll}
\hline Experimental & & & Numerical \\
\cline { 5 - 5 } Mode & $f_{\text {EXP }}[\mathrm{Hz}]$ & & Mode & $f_{\text {NUM }}[\mathrm{Hz}]$ \\
\hline 1st & 3.69 & & 1st & 3.79 \\
2nd & 5.12 & 4 th & 5.34 \\
3rd & 6.29 & 7 th & 6.23 \\
4th & 7.23 & 10th & 6.61 \\
\hline
\end{tabular}

the correlation the modal frequency of the first vibration mode, i.e. the mode featuring the highest participation factor $[7,16]$. The updating parameters initially selected are the moduli of elasticity of columns and nave, and the boundary conditions of the columns. Yet, considering that several parameters cannot be correctly updated by using just one reference as the inverse problem is highly ill-conditioned, the columns were finally considered as fully constrained and only the Young's moduli of columns and nave were updated. Final values of $30 \mathrm{GPa}$ and $12 \mathrm{GPa}$ are obtained for the columns and the remaining masonry sub-structures, respectively. Given the high compressive stresses present in the columns because of their small cross section as well as the better quality of limestone blocks composing these bearing elements in comparison to the quality of masonry used to build the other sub-structures, both the values of Young's moduli are considered reasonable.

\subsection{Safety assessment for gravity loading}

In order to proceed with the evaluation of the safety level of the church, a first analysis was carried out under vertical loading assuming linear elastic behaviour of the material. The results indicated that the maximum deformations occur in the main nave of the church and are rather small. Fig. 9 shows the typical arch shape deformation of the transversal section of the nave (central arcade), where maximum displacements of $3.7 \mathrm{~mm}$ and $21 \mathrm{~mm}$ are found for the vault key in vertical direction and for the upper part of the columns in horizontal direction, respectively. Unlike the north wall, the south wall does not show any outward displacement, sign of its minor sensitivity to the thrust action generated by the vault above. The stresses present in the structure are within the linear range of the material, e.g. the maximum compressive stresses in the columns are lower than $3.30 \mathrm{MPa}$. Tensile stresses up to $0.6 \mathrm{MPa}$ are found in the nave vault, but they are very localized and the compressive stresses do not exceed 4.0 MPa in the critical areas where the ribs spring. Altogether, the average tensile stresses present in the structure are below the tensile strength of masonry.

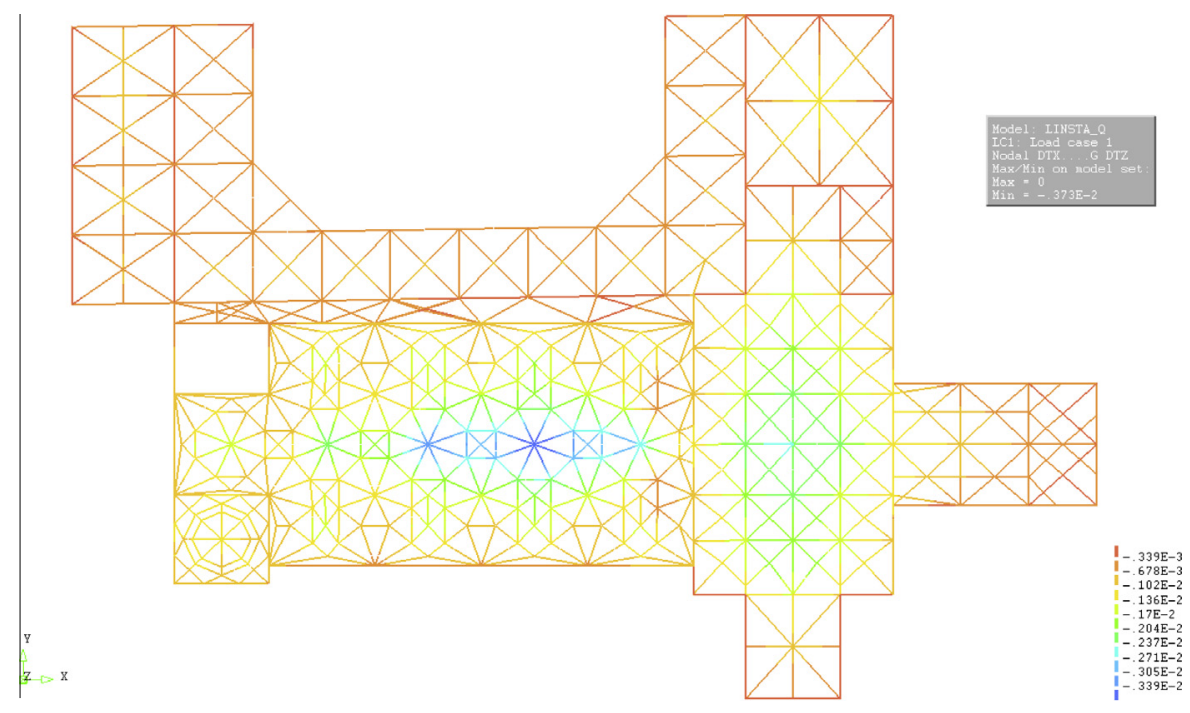

(a)

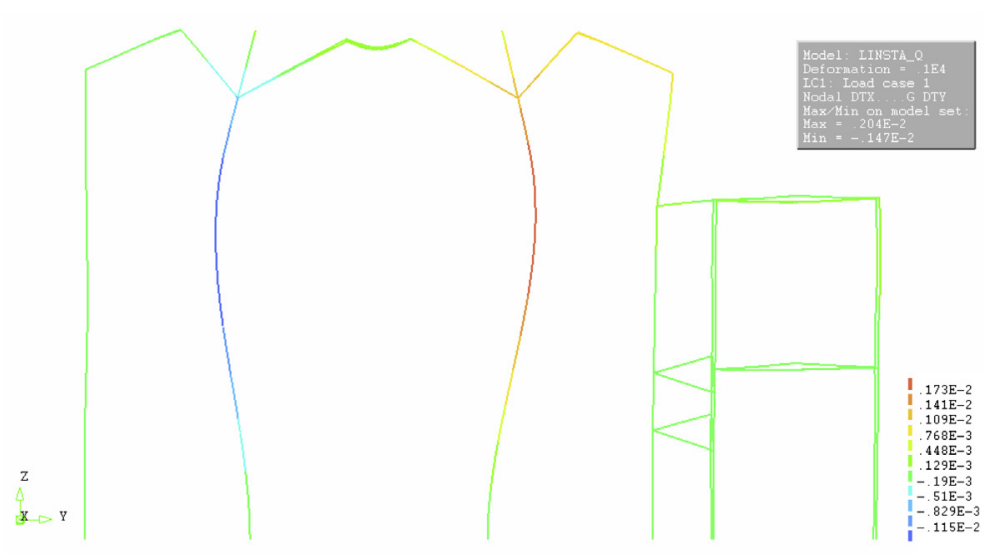

(b)

Fig. 9. Linear static analysis for vertical loads. Deformed mesh of the church: (a) plan and (b) central arcade of the nave. 


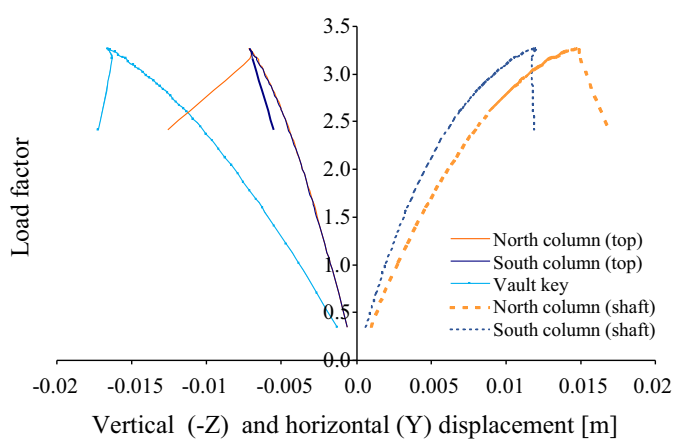

(a)

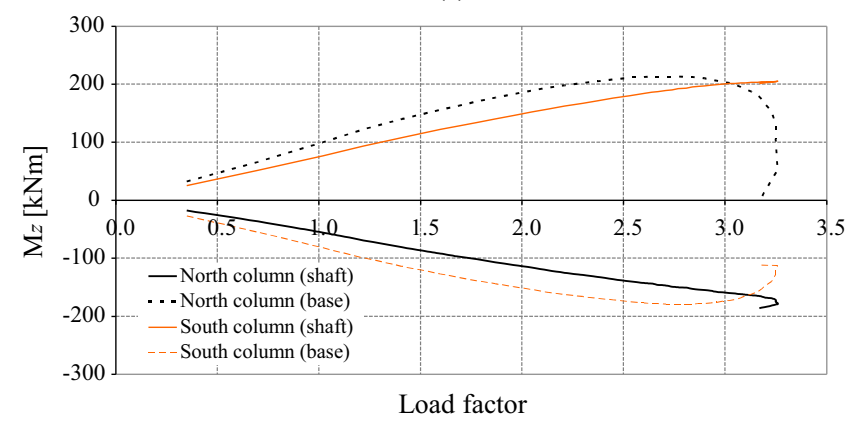

(b)

Fig. 10. Nonlinear static analysis for vertical loads: (a) capacity curve; (b) momentload factor diagram for the central arcade of the nave.

As columns and vault resulted to be the most critical substructures of the system, a second nonlinear static analysis under vertical loading was carried out in order to catch the possible occurrence of non-linear phenomena in these elements and to assess the global structural capacity of the church for gravity loading. A uniform distribution proportional to the mass is adopted for the loads (uniform pushover). The results of the nonlinear analysis are shown in Figs. 10a and 11 in terms of post-peak deformed shape and load-displacement diagram for both vault key and columns of the central arcade. Here, the load factor represents the ratio between the self-weight of the structure and the applied load. It is highlighted that the response of the church is severely affected by the structural behaviour of the supports, especially in regard to the north column which shows a sudden loss of bearing capacity associated with increasing horizontal and vertical displacements (up to $13 \mathrm{~mm}$ ) which affect in turn the vault key. The ultimate load factor is 3.25 and corresponds to the collapse of the north column due to combined normal and flexural actions. For the same peak value the nave vault exhibits a nonlinear behaviour with diffuse cracking. Note that the maximum 'flexural moment' at the base of the columns is attained for a load factor of 2.7 (Fig. 10b), but the stress redistribution associated with the nonlinear behaviour of the supports delays the failure. Therefore, the crushing of the north column occurs for increasing compressive stresses of decreasing eccentricity.

\subsection{Final remarks}

Notwithstanding the complexity of the case study, the numerical analyses carried out allowed to better understand the structural behaviour of the church and to conclude that: (a) the bearing capacity of the church under gravity loading is considerably affected by the nave columns behaviour; (b) the potential collapse mechanism is associated with the failure of the north column of the central arcade; (c) even though the columns are very slender, the structural performance of the church under vertical loading is good.

\section{Description of the monitoring systems}

To fully characterize the current health state of the monument, to detect any possible change due to the occurrence of damage and to study the influence of varying environmental parameters on both static and dynamic behaviour, two monitoring systems were installed in the main nave of the church $[1,7,12,14]$. Owing to the different technical characteristics and sampling rates of the data acquisition, the two monitoring systems are physically separated. The type and location of sensors have been chosen according to the features to be extracted and in conformity with the directions of IGESPAR, former IPPAR (Portuguese Authority for the Architectural Heritage), with the purpose of minimizing the visual impact of the systems in the church [1].

\subsection{Static monitoring system}

The static monitoring system is active since June 2005 and it is composed by:

- Two uniaxial tilt meters (TL1 and TL2) with a measurement range of $\pm 1.5^{\circ}$ and a resolution of $0.03^{\circ}$. The two tilt meters are located at the nave extrados on top of the columns with larger out of plumb and are positively oriented to North. TL1 measures the inclination of the North column (C1) and TL2 tracks the inclination of the South column (C2);

- Six surface temperature sensors (TS1 to TS6), with a measurement range varying from $-20^{\circ} \mathrm{C}$ to $+100^{\circ} \mathrm{C}$ and a resolution of $0.2^{\circ} \mathrm{C}$. Two sensors are installed at the nave extrados on top of the observed columns and four sensors are installed in the north and south sidewalls. TS1 and TS2 register the temperature of outer and inner side of the north wall, respectively; TS4 and TS3 measure the temperature of outer and inner side of the south wall, respectively; and TS5 and TS6 record the temperature on top of the north and south columns;

- One data logger (D) for the data acquisition, provided with a Global System for Mobile (GSM) communication device to enable data remote downloading by phone line. The data logger is located inside a protection box in the bell tower.

On April 2007 the following devices were added to the permanent equipment:

- One combined sensor to measure air temperature and relative humidity $(\mathrm{TH})$. The temperature range goes from $-20^{\circ} \mathrm{C}$ to $+70{ }^{\circ} \mathrm{C}$ with a resolution of $0.2{ }^{\circ} \mathrm{C}$ and the relative humidity range varies from $0 \%$ to $100 \%$, with a resolution of $2 \%$;

- One ultrasonic 2D anemometer (W) to measure wind velocity and direction, with an operating temperature between $-35{ }^{\circ} \mathrm{C}$ and $+70{ }^{\circ} \mathrm{C}$, an operating humidity between $5 \%$ and $100 \%$, a wind velocity range between 0 and $60 \mathrm{~m} / \mathrm{s}$ with a resolution of $0.01 \mathrm{~m} / \mathrm{s}$, and a wind direction range of $360^{\circ}$ with a resolution of $1^{\circ}$.

The location of all devices is schematized in Fig. 12. Since the columns determine the nave structural behaviour (see Section 4), the monitoring system focuses on measuring the deformations of these elements. In order to catch daily temperature variations, the recordings are taken with a sampling rate of one per hour, equivalent to twenty-four events per day.

\subsection{Dynamic monitoring system}

The dynamic monitoring system is operating since April 2005 and it is composed by the same devices used for the dynamic 


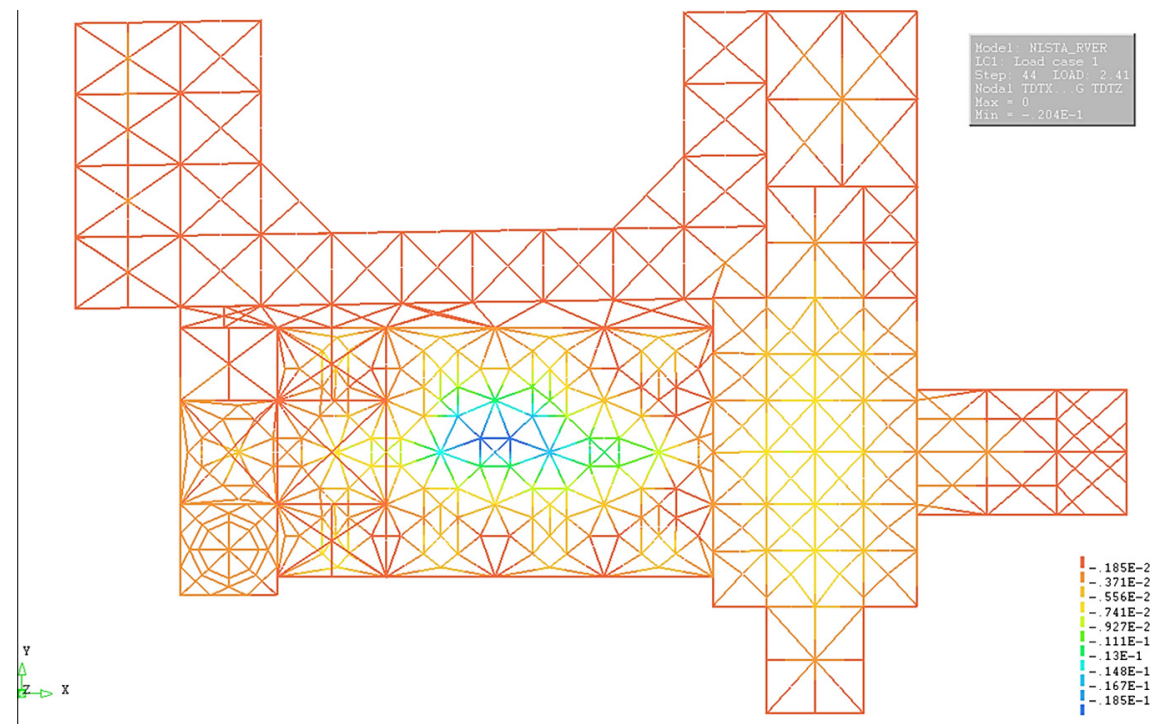

(a)

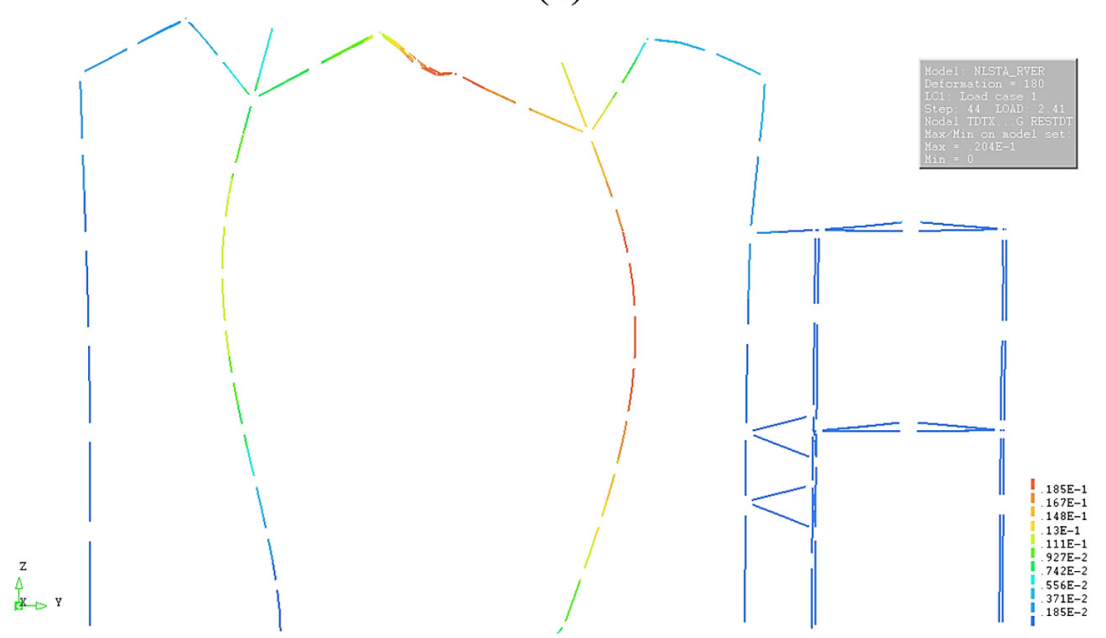

(b)

Fig. 11. Nonlinear static analysis for vertical loads. Post-pic deformation of the church $(\mathrm{LF}=2.41)$ : (a) plan and (b) central arcade of the nave.

identification (Section 3), namely two synchronized strong motion recorders (R) and two tri-axial force balance accelerometers (A1 and A2), see Fig. 13: sensor A1 is located at the base of the structure near the chancel and is connected to the master recorder; sensor A2 is installed on the nave extrados in the location chosen as reference point during the AVTs and is connected to the slave recorder. Both recorders are installed near sensor A1 and are mutually connected by an enhanced interconnection network which allows common trigger and time programmed records. In particular, the monitoring system is set to acquire the response of the church according to the following schedule:

- 10 min records every month to compare the dynamic response of the church over time and to separate the influence of changing environmental conditions on the structural behaviour;

- 10 min records every hour, one day per season, in order to observe the daily seasonal fluctuations of the ambient parameters and their effect on the dynamic response of the church;

- Random records to measure the loading excitation anytime a micro-tremor occurs. For this purpose the acceleration level for sensor A1 (on the base) is fixed to $0.5 \mathrm{mg}$ in all directions and for sensor A2 (on the main nave) is set to $10 \mathrm{mg}$ in $x$ direction and to $50 \mathrm{mg}$ for $y$ and $z$ directions.

Since the force balance accelerometers are not enough to monitor the dynamic behaviour of the church in terms of mode shapes, only the global modal parameters (frequencies and damping coefficients) are being analysed. According to the results of the AVTs, all events are recorded with a sampling frequency of $100 \mathrm{~Hz}$.

\section{Monitoring results and environmental effects}

\subsection{Static behaviour of the church}

The analysis of the static monitoring data is carried out over a nine-year span, viz. from 23rd June 2005 to 4th July 2014, during which 74,212 events were collected. The main goals are: to identify the occurrence of possible unstable phenomena or damage mechanisms and to understand whether and to which extent ambient variables do affect the static response of the church. In order to study the correlation with as many environmental parameters as 


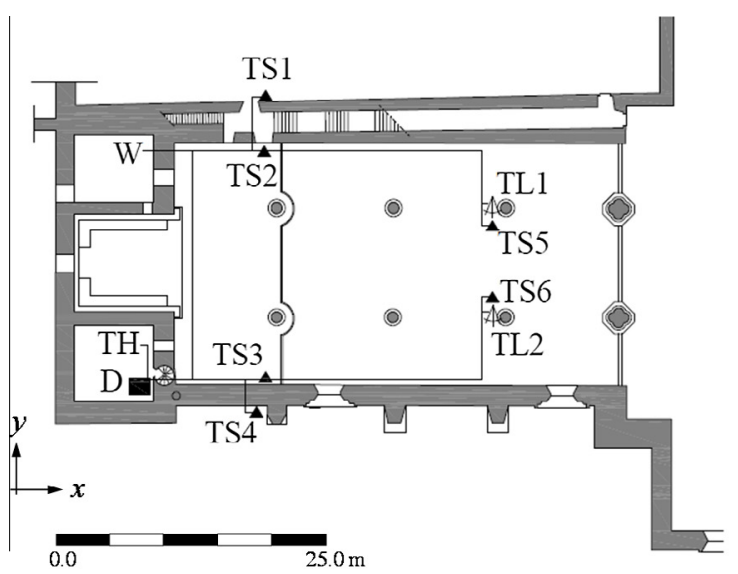

(a)

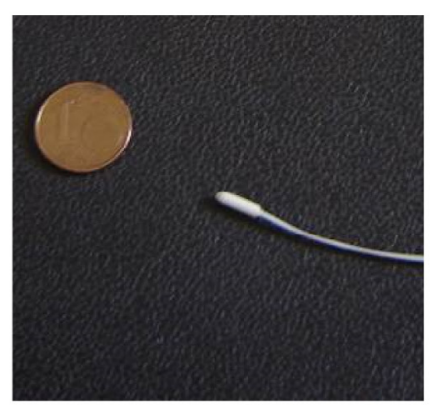

(c)

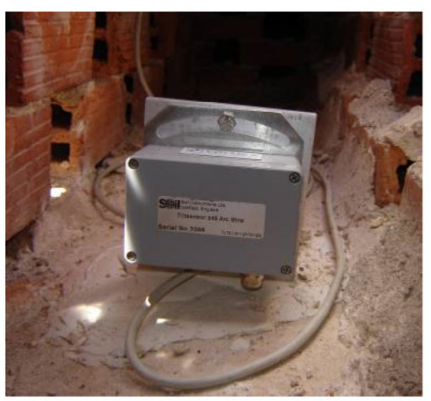

(d)

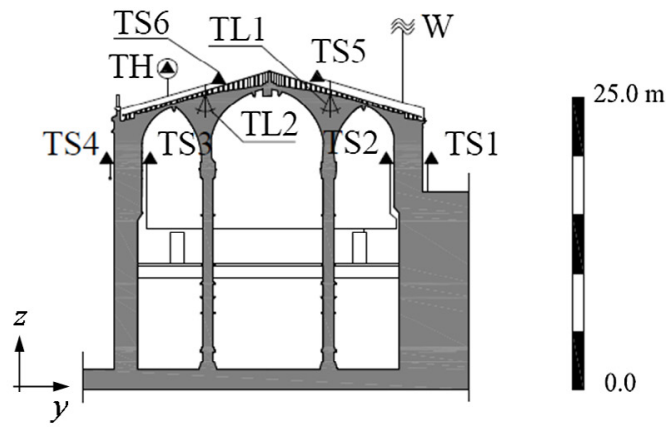

(b)

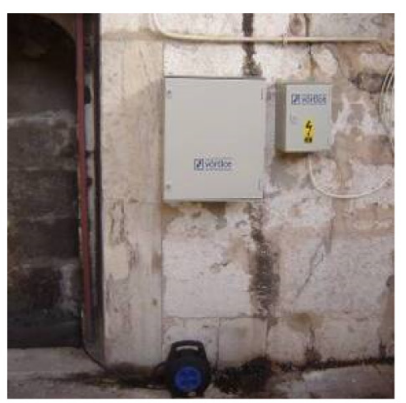

(e)

Fig. 12. Static monitoring system: (a) and (b) sensors location; (c) temperature sensor; (d) tilt meter; and (e) data logger.

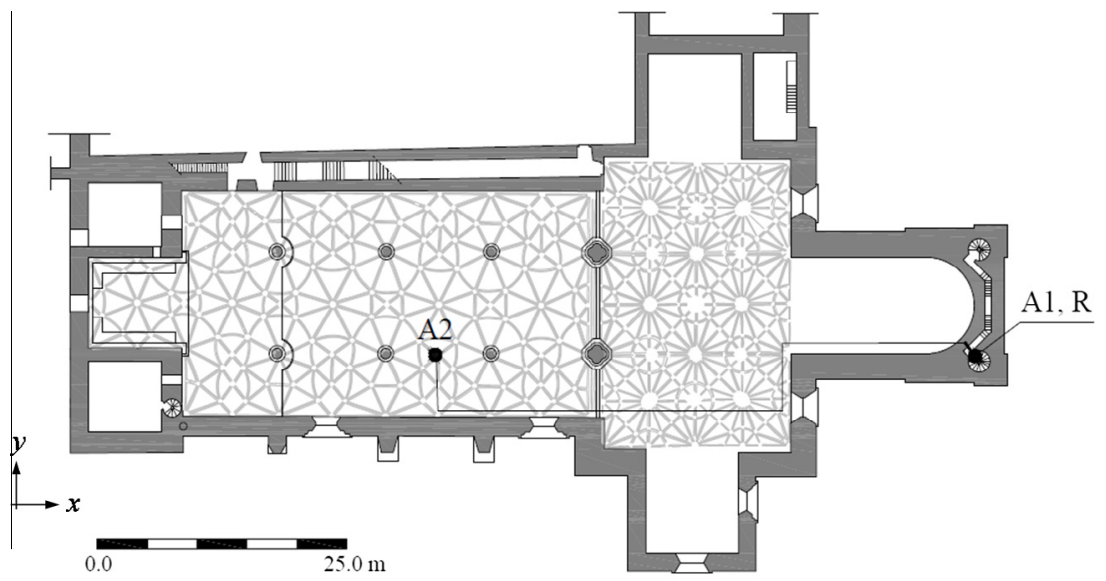

(a)

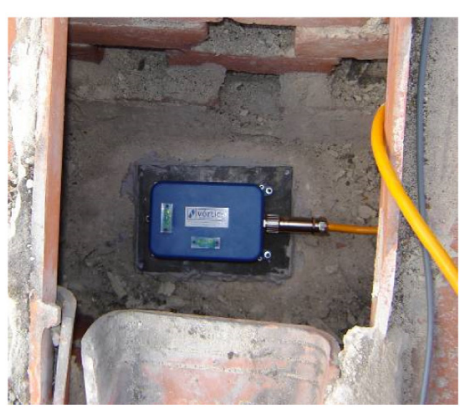

(b)

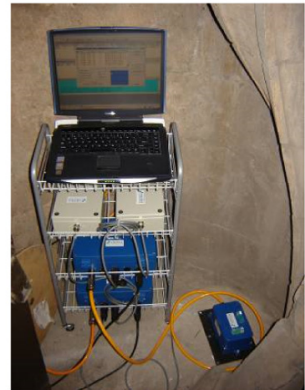

(c)

Fig. 13. Dynamic monitoring system [7]: (a) sensors location; (b) accelerator $A 2$ at the roof level; (c) battery of recorders and accelerator $A 1$ at the base level. 


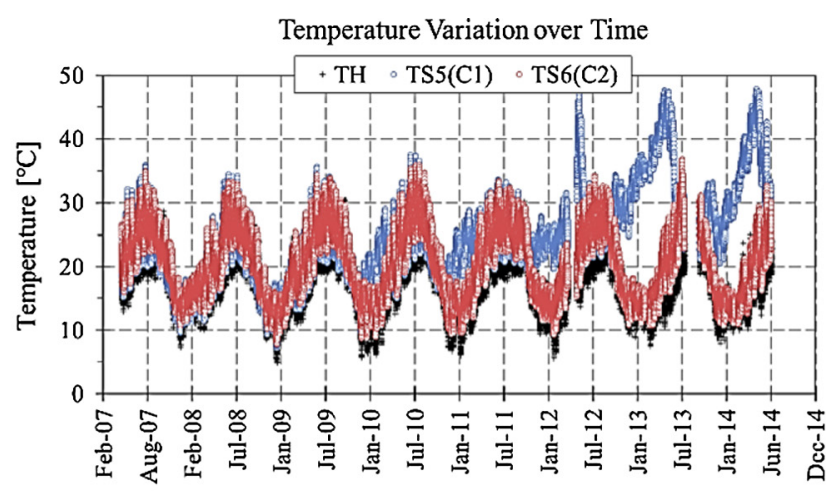

Date

(a)

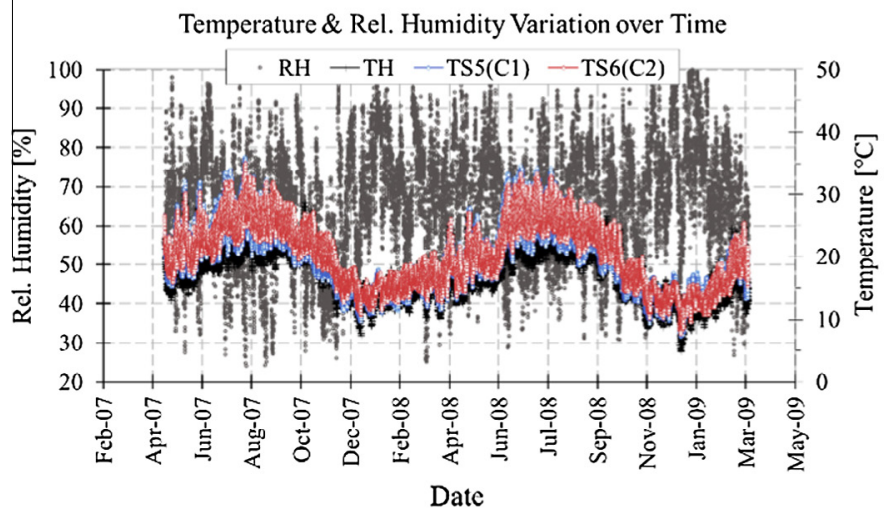

(c)

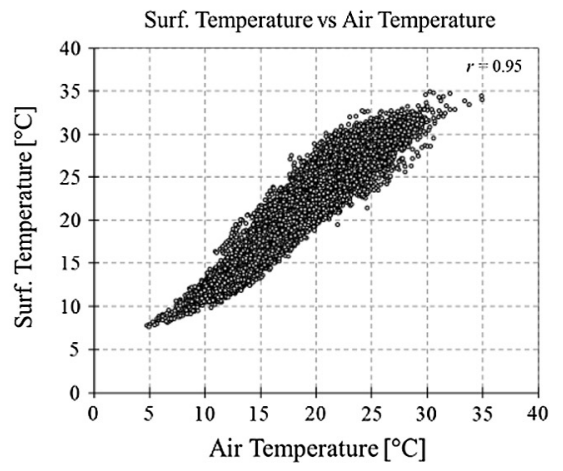

(e)

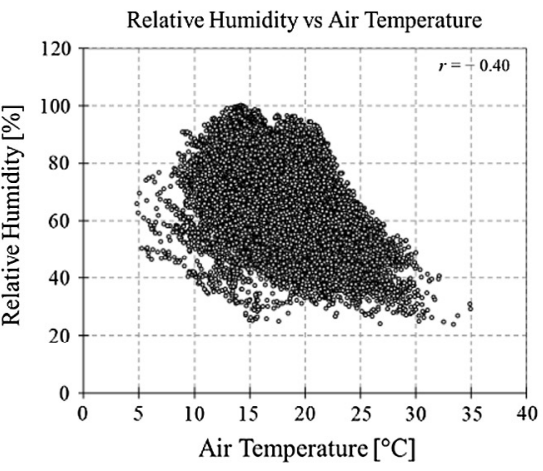

(f)

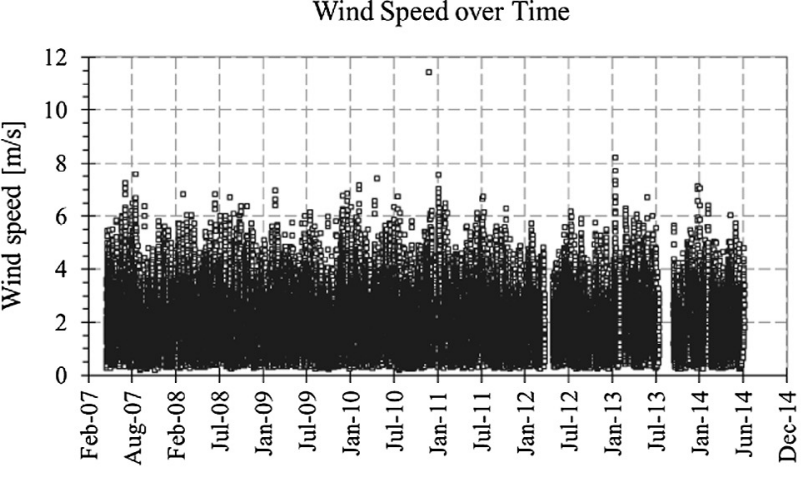

Date

(b)

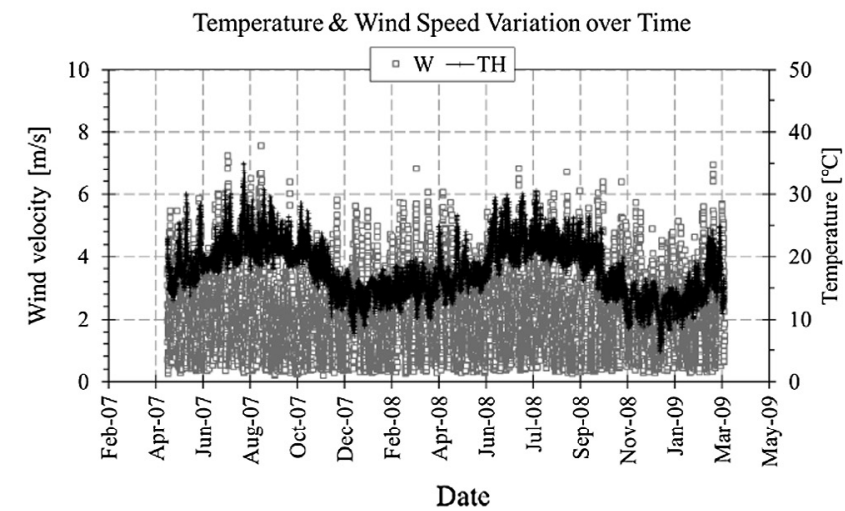

(d)

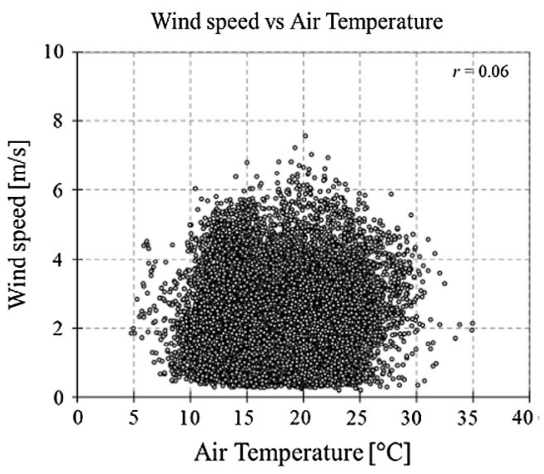

(g)

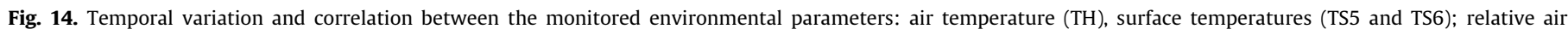
humidity (RH); and wind speed (W).

possible, this section presents the results beginning from 23rd April 2007. Fig. 14a shows the evolution of the air temperature along with the columns' surface temperature over nearly seven cycles, where each one-year cycle embraces four seasonal fluctuations. As it can be observed, air and surface temperatures are characterized by the same trend, with the exception of the surface temperature of the north column (TS5) which presents an odd upward shift since May 2012, probably caused by the detachment of the sensor from the surface. Thus, after this date, the measurements recorded by sensor TS5 are deemed unreliable and will not be considered in the following analysis. Regarding the wind (Fig. 14b), it is noted that the instantaneous speeds recorded over time range from zero to about $12 \mathrm{~m} / \mathrm{s}$ and the average speed is always below $3 \mathrm{~m} / \mathrm{s}$, meaning that the energy available in the wind is rather low.

A close-up of the period between April 2007 and March 2009 is displayed in Fig. 14c and d to better visualize the air temperature (TH) trend and its variation with respect to surface temperature (TS6), relative humidity (RH) and wind speed (W). The correlation coefficients between the investigated variables are indicated as well (Fig. 14e-g). As expected, air temperature and surface temperature show a strong positive linear correlation with $r$ almost close to 1 , whereas air temperature and relative humidity present an inverse relationship: as the temperature increases the humidity decreases and vice versa, but the correlation between these two variables is not very strong $(r=-0.40)$. Finally, no relationship 
Table 4

Statistics of the environmental variables monitored from 23/06/2005 to 04/07/2014.

\begin{tabular}{lrcccc}
\hline Results & $\begin{array}{l}\text { Surf. Temp. } \\
\text { TS5 }\left[{ }^{\circ} \mathrm{C}\right]\end{array}$ & $\begin{array}{l}\text { Surf. Temp. } \\
\text { TS6 }\left[{ }^{\circ} \mathrm{C}\right]\end{array}$ & $\begin{array}{l}\text { Air } \\
\text { Temp. } \\
{\left[{ }^{\circ} \mathrm{C}\right]}\end{array}$ & $\begin{array}{l}\text { Rel. } \\
\text { Humidity } \\
{[\%]}\end{array}$ & $\begin{array}{l}\text { Wind } \\
\text { speed } \\
{[\mathrm{m} / \mathrm{s}]}\end{array}$ \\
\hline Average & 24.36 & 20.35 & 18.0 & 67.41 & 2.07 \\
St. dev. & 7.17 & 5.43 & 4.46 & 14.36 & 1.16 \\
CV [\%] & 29.42 & 26.67 & 24.75 & 21.31 & 56.0 \\
Maximum & 47.89 & 36.81 & 35.66 & 100.01 & 11.44 \\
Minimum & 7.15 & 7.7 & 4.79 & 17.1 & 0.19 \\
\hline
\end{tabular}

exists between air temperature and wind speed, being the correlation coefficient $r$ almost close to zero. Table 4 summarizes the statistical results relevant to the monitored environmental parameters.

Analysing the tilt data, it is found that the two columns of the central arcade are moving in north-south direction with in-phase cyclic oscillations of different amplitudes (Fig. 15a) which follow a liner decreasing trend. Column C2 is leaning towards south (negative direction) with an average tilting rate of $1.3 \times 10^{-2} \mathrm{~mm} / \mathrm{m}$ per year and oscillations ranging between $0.10 \mathrm{~mm} / \mathrm{m}$ and $-0.29 \mathrm{~mm} / \mathrm{m}$. Column $\mathrm{C} 1$ is also leaning towards south, but with a wider oscillation range varying from $0.17 \mathrm{~mm} / \mathrm{m}$ to $-0.30 \mathrm{~mm} / \mathrm{m}$ and a tilting rate of $2.0 \times 10^{-2}$ $\mathrm{mm} / \mathrm{m}$ per year, $35 \%$ faster than column $\mathrm{C} 2$. Assuming the centre of rotation at the bottom of each column and rigid body
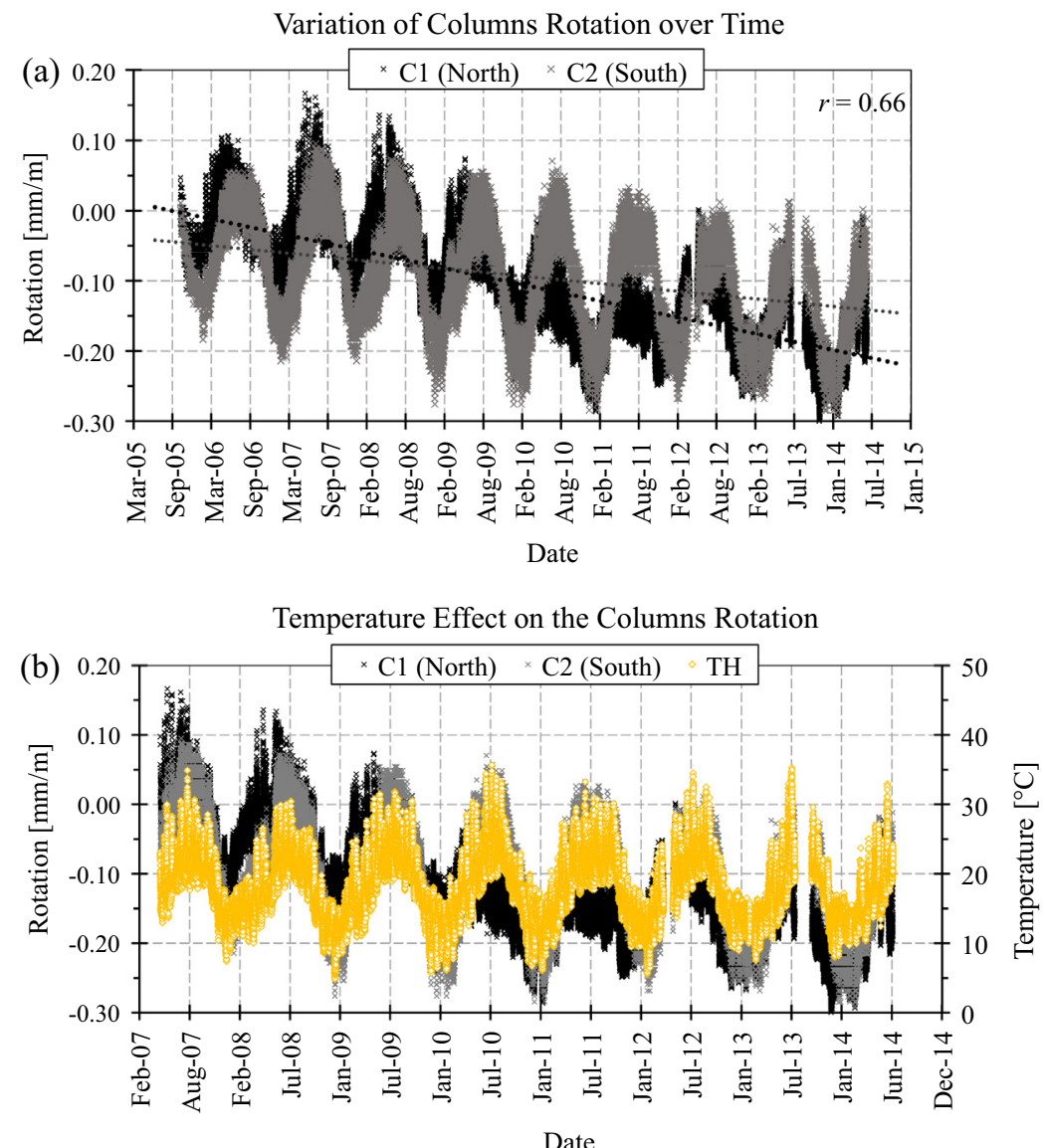

Rotation of the North Column (C1) vs Air Temperature TH

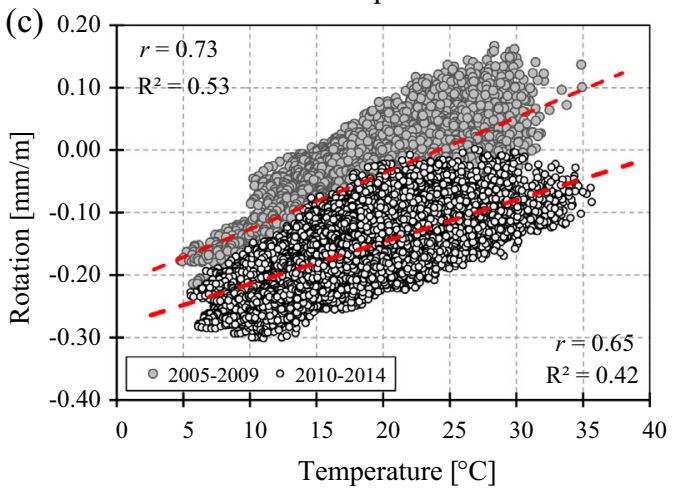

Rotation of the South Column (C2) vs Air Temperature TH

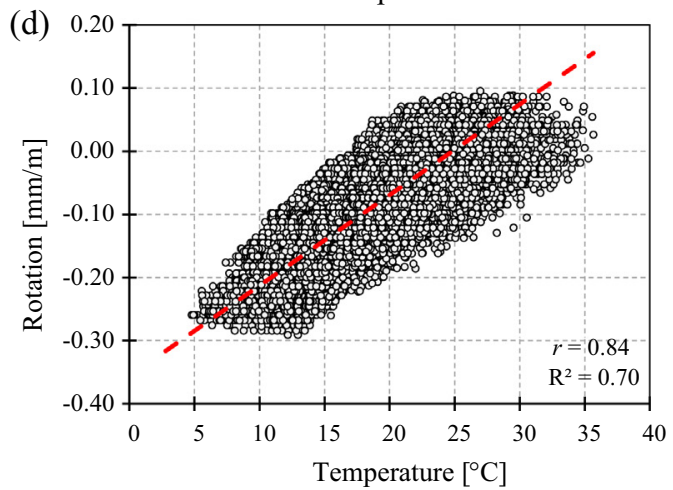

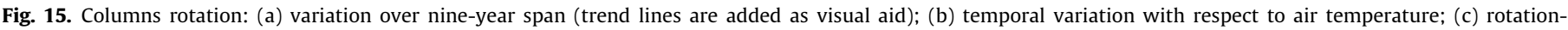
temperature correlation for column $\mathrm{C} 1$; and (d) rotation-temperature correlation for column $\mathrm{C} 2$. 
movements, the horizontal displacements at the top of the columns range between $0.21 \mathrm{~mm}$ and $0.32 \mathrm{~mm}$. The inspection of Fig. 15b reveals that the cyclic oscillations of the columns considerably suffer from the seasonal fluctuations of the temperature: when the temperature goes up, the columns do rotate towards north, whereas when the temperature goes down, the columns do lean towards south. However, after each cycle, the columns never recover their original position, but show an increasing residual tilt towards south which indicates that the out-of-plumbness of both supports is permanent and keeps on raising over time, especially in regard to column $\mathrm{C} 1$. This behaviour is further confirmed by the analysis of the rotation-temperature relationships which show a remarkable change of the slope of the regression line for the north column C1 (Fig. 15c), although the range of temperature variation remains almost the same. On the contrary, the rotationtemperature relationship of column C2 does not vary over time and results to be much stronger, with coefficients of correlation $r$ and determination $R^{2}$ equal to 0.84 and 0.70 , respectively (Fig. 15d).

In order to investigate whether exogenous phenomena related to relative humidity and wind may influence somehow the columns rotation, the tilt data are also analysed with respect to these environmental parameters. Fig. 16 plots the results relevant to the last two-year span. As conceivably verified by evaluating the coefficients of correlation, a weak correlation is found between the relative humidity and the rotation of the north column $\left(r_{\mathrm{C} 1}=-0.30\right)$, whereas almost no correlation exists between the relative humidity and the rotation of the south column $\left(r_{\mathrm{C} 2}=-0.15\right)$. Given the low value of average wind speed recorded over time, no direct influence of the wind on the static behaviour of the columns is detected.

\subsection{Dynamic behaviour of the church}

In this section the results from the dynamic monitoring campaign carried out between 24th August 2005 and 28th April 2008 are presented and analysed with respect to four independent ambient variables: air temperature, relative humidity, wind and level of excitation. During this period, a total number of 1809 datasets were acquired, of which $40 \%$ corresponds to programmed events of 10 min (monthly and seasonal events) and 60\% corresponds to triggered events with an average duration of about $75 \mathrm{~s}$. As datasets of various duration are characterized by different accuracy and uncertainty, the estimation of the dynamic features is performed by only processing the programmed events. Since higher vibration amplitudes are expected at the roof level, the analysis will concern the programmed events recorded in sensor A2.

\subsubsection{Automated modal parameter estimation}

The estimation of the global dynamic characteristics of the church is carried out through an automatic processing algorithm implemented in MATLAB [22] that makes use of the Stochastic Subspace Identification (SSI) method [19] as fulcrum for the features extraction process. Like all parametric system identification techniques $[9,11,23]$, a user-defined integer is required, i.e. the maximum model order. In the present application, after testing different values of model order in the range 20-100 with increments of 10 , a maximum model order of 50 is selected. As an example, Fig. 17 shows the stabilization diagrams for the chosen model order before and after clearing. The final physical modes are selected according to a clustering approach. A cluster is a set of data points whose grouping meets similarity criteria, e.g. consistency
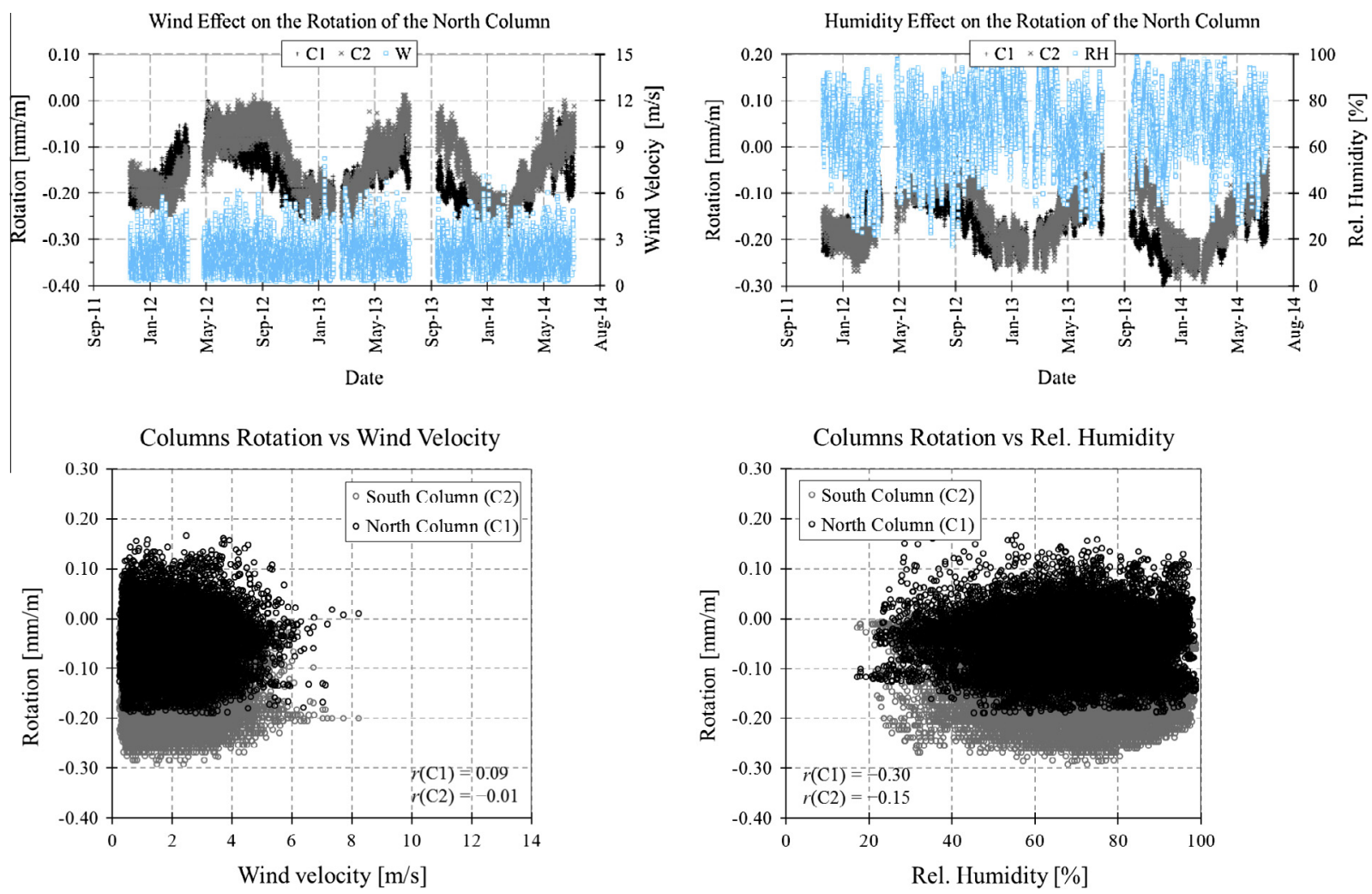

(a)

(b)

Fig. 16. Temporal variation and correlation of columns rotation with respect to (a) wind speed and (b) relative humidity: close-up of the period from $01 / 12 / 2011$ to $04 / 07 /$ 2014. 


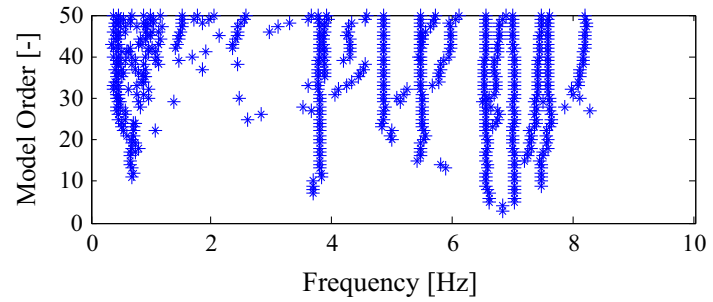

(a)

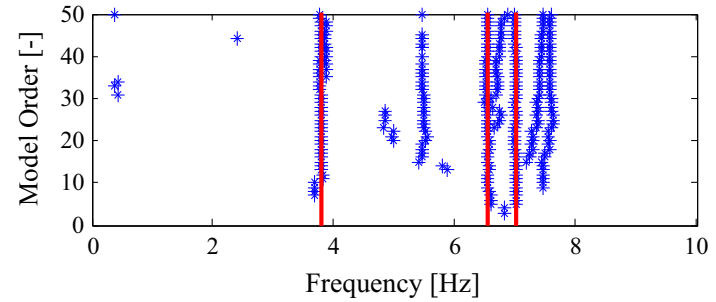

(b)

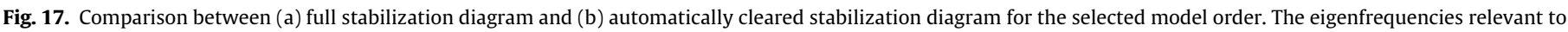
the stable modes are plotted as vertical lines on top of the cleared diagrams.

in terms of estimated frequencies as well as damping coefficients. For each model order $i, n$ clusters of datasets are created based on the following criteria:

$$
\begin{aligned}
& d_{c v, i}=\left|f_{c v}-f_{i}\right| \leq f_{\text {thr }} \\
& \xi_{\text {thr,min }} \leq \xi_{i, i+1} \leq \xi_{\text {thr,max }}
\end{aligned}
$$

in which $d_{(c v, i)}$ is the Euclidian distance, $f_{c v}$ and $f_{t h r}$ stand for frequency control value and frequency threshold value, while $\xi_{t h r, m i n}$ and $\xi_{\text {thr,max }}$ indicate minimum and maximum damping coefficient threshold values, respectively. Clusters whose elements meet the Frequency Assurance Criterion (FAC) and the Modal Assurance Criterion (MAC) are selected for the candidate modes:

$F A C=\left|\frac{f_{i+i}-f_{i}}{f_{i}}\right| \leq F A C_{t h r}, \quad k=[1,2, \cdots n]$

$\min \left(M A C_{i, i+1}\right)_{k} \leq M A C_{t h r}, \quad k=[1,2, \cdots n]$

Unlike spurious modes, physical modes are characterized by poles with nearly identical frequencies $f_{i}$, damping ratios $\xi_{i}$ and mode shapes $\boldsymbol{\varphi}_{i}$. Although only a single measurement point (A2) is available in this case, the MAC is not discarded but exploited as a relative modal amplitude comparison of the identified poleweighted mode shape component $\phi_{i o}$ to assist in the selection of the physical modes along with the FAC and perform a more accurate clustering analysis.

The characteristic values of each physical mode are computed by averaging frequency and damping values obtained iteratively per each model order. Finally, the whole routine is looped in order to estimate the characteristic values of each mode throughout the monitoring period along with their 95\% confidence intervals. In this regard, it is stressed that, dealing with a large number of data, a normal distribution is assumed and the two-sided confidence limits around each predicted value $\hat{y}$ are evaluated as follows:

$\left[\hat{y}-1.96 \sigma_{y}, \hat{y}+1.96 \sigma_{y}\right]$

Table 5

Acquisition and data processing parameters for the automated modal identification.

\begin{tabular}{lll}
\hline Parameters & Description & Value \\
\hline Acquisition parameters & Sampling rate [Hz] & 100 \\
& Signal duration [s] & 600 \\
& Sampling interval [h] & Variable \\
Processing parameters & State-space model order & 50 \\
& Decimation factor & 5 \\
& Frequency range & $3.0-8.0$ \\
& Damping range & $0.1-5.0$ \\
& FAC threshold & 0.06 \\
& MAC threshold & 0.90 \\
& Frequency control vector & {$[3.75 .26 .67 .3]$} \\
\hline
\end{tabular}

where $\sigma_{y}$ is the estimated standard deviation of $\hat{y}$ and 1.96 is found from a statistical t-distribution table. The definition of such confidence intervals provides an unbiased criterion to identify the occurrence of damage if the predicted values of new observations do not lie within the estimated confidence limits.

In this study, the control values required for the automated (operational) modal analysis are defined using as reference parameters the results from the previous ambient vibration tests (see Section 3.2). Before starting the procedure, a preliminary preprocessing task is performed, including decimation, de-trending and band-pass filtering of the collected signals. The adopted acquisition and data processing parameters are summarized in Table 5. The datasets not matching the sorting criteria imposed by the control values are discarded during the process.

\subsubsection{Results of the long-term dynamic monitoring}

In the automated dynamic identification of the church, three modes are found, namely the first, the third and the fourth mode. The second vibration mode could not be estimated accurately. Fig. 18 presents the frequencies tracking over the monitoring period, whereas the statistical values of natural frequencies and modal damping ratios for the identified modes are given in Table 6 together with the statistics of the measured environmental variables. The magnitude of the ambient noise level is here expressed by the Root Mean Square (RMS) of the three acceleration channels recorded in sensor $\mathrm{A} 2$. The standard deviations and the coefficients of variation (CVs) of the natural frequencies allow to understand that environmental variables have a strong influence, especially for mode 1 where the CV equals $2.20 \%$, while mode 4 seems to be less influenced by environmental factors ( $C V=1.11 \%$ ). As far as the estimation of the damping coefficients is concerned, as expected, the results point out higher dispersions: the CV varies

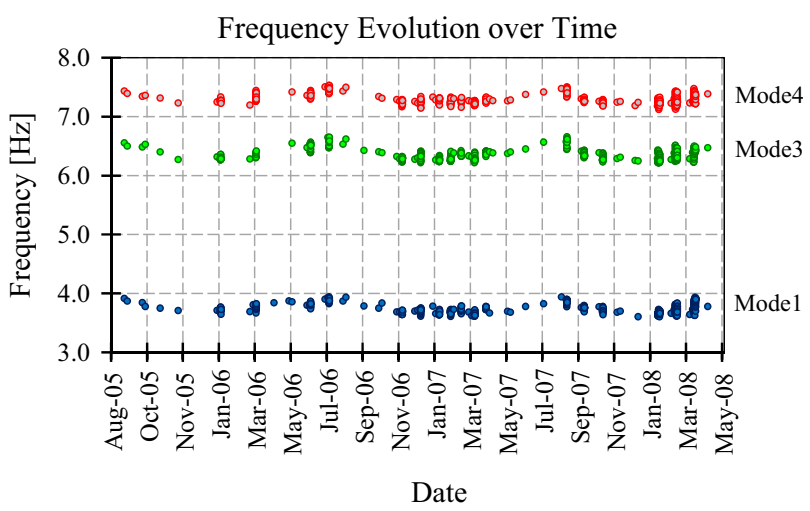

Fig. 18. Variation of the identified natural frequencies during the monitoring period. 
Table 6

Statistics of ambient variables and global modal parameters monitored from 24/08/2005 to 28/04/2008.

\begin{tabular}{|c|c|c|c|c|c|c|c|c|c|c|}
\hline Results & Temp. $\left[{ }^{\circ} \mathrm{C}\right]$ & $\mathrm{RMS}_{(y)}[\mathrm{mg}]$ & Wind $^{\mathrm{a}}[\mathrm{m} / \mathrm{s}]$ & Rel. Hum ${ }^{\mathrm{a}}[\%]$ & $f_{1}[\mathrm{~Hz}]$ & $\xi_{1}[\%]$ & $f_{3}[\mathrm{~Hz}]$ & $\xi_{3}[\%]$ & $f_{4}[\mathrm{~Hz}]$ & $\xi_{4}[\%]$ \\
\hline Average & 19.79 & 0.013 & 2.15 & 65.25 & 3.74 & 2.51 & 6.36 & 0.89 & 7.29 & 1.04 \\
\hline St. dev. & 5.39 & 0.004 & 1.23 & 14.51 & 0.08 & 0.57 & 0.11 & 0.31 & 0.08 & 0.41 \\
\hline CV [\%] & 27.26 & 26.95 & 57.34 & 22.24 & 2.20 & 22.67 & 1.74 & 34.38 & 1.11 & 39.45 \\
\hline Minimum & 7.66 & 0.009 & 0.19 & 24.03 & 3.60 & 0.74 & 6.21 & 0.44 & 7.09 & 0.29 \\
\hline Maximum & 35.13 & 0.068 & 7.57 & 98.60 & 3.94 & 4.32 & 6.78 & 3.48 & 7.53 & 3.14 \\
\hline
\end{tabular}

a The statistics refer to the period from $23 / 04 / 2007$ to $28 / 04 / 2008$.
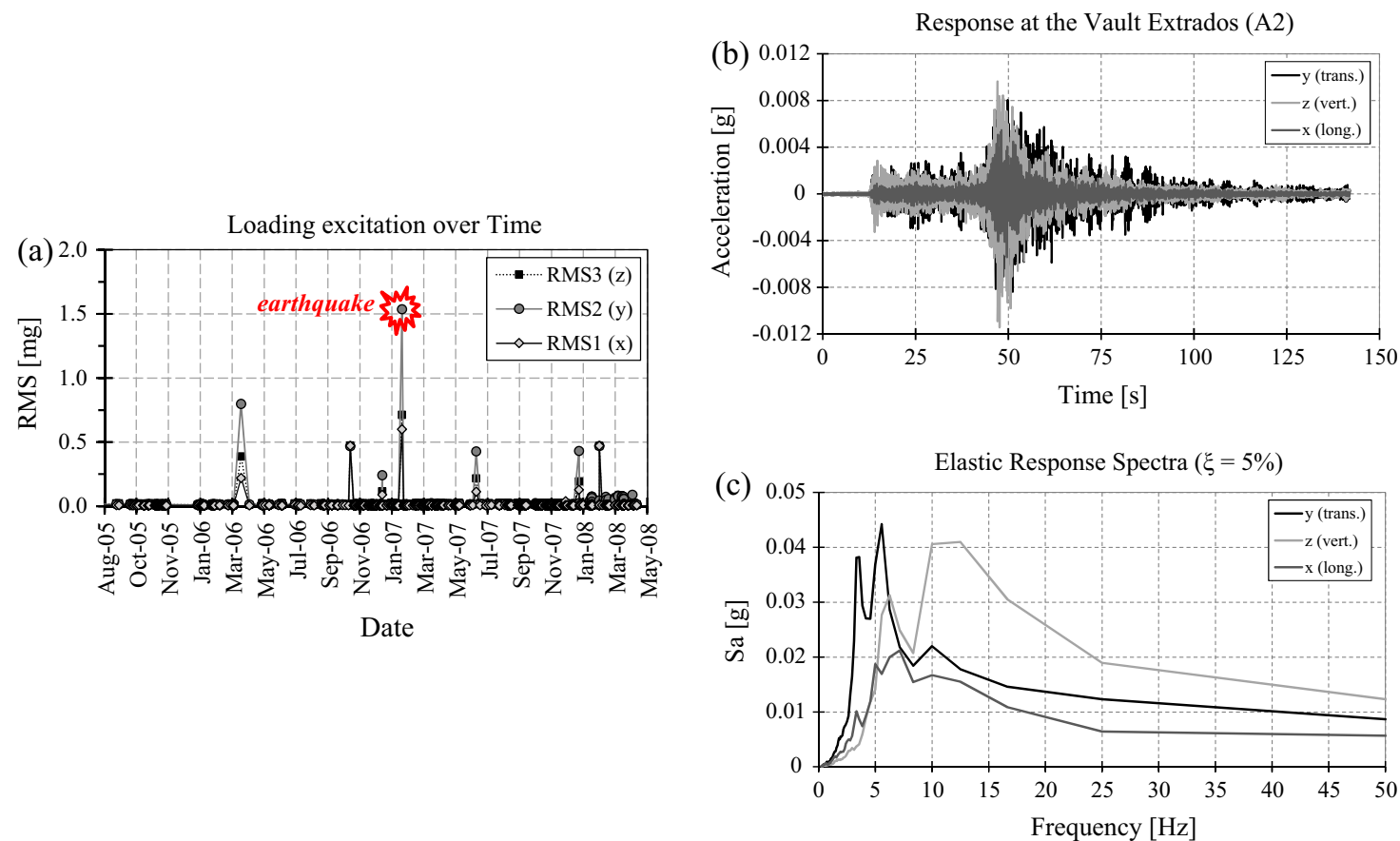

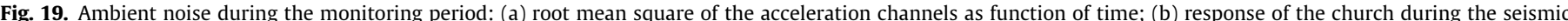
event of 12/02/2007; and (c) corresponding elastic response spectra $(\xi=5)$.

in fact between $22 \%$ of mode 1 and $40 \%$ of mode 4 . The triggered events were analysed with the only purpose of gaining a better insight into the level of ambient excitation throughout the monitoring period. As shown in Fig. 19a, the ambient noise is very low but a few isolated micro-tremors, mainly due to rally events and concerts taking place in the surrounding area, are discernible. It is worth noting that on 12 February 2007, at 10:35 am, a moderate earthquake of magnitude $\mathrm{M}_{w}=6.1$ and with epicentre offshore Southwest Iberia occurred. The Monastery felt the ground shaking and its response was acquired by the strong motion recorders installed in the church (Fig. 19b). As it can be observed from the inspection of Fig. 19c, the peaks of the frequency content of the elastic response spectra fell exactly within the range of identified

Table 7

Frequency values before and after the seismic event of 12/02/2007.

\begin{tabular}{|c|c|c|c|c|c|c|c|}
\hline \multirow[t]{2}{*}{ Mode } & \multicolumn{2}{|l|}{$f[\mathrm{~Hz}]$} & \multirow[t]{2}{*}{$\Delta f[\%]$} & \multicolumn{2}{|c|}{ Confidence Interval $^{\mathrm{a}}[\mathrm{Hz}]$} & \multicolumn{2}{|c|}{$r_{\text {TH-FRQ }}[\%]$} \\
\hline & Before & After & & $\begin{array}{l}\text { Lower } \\
\text { Bound }\end{array}$ & $\begin{array}{l}\text { Upper } \\
\text { Bound }\end{array}$ & Before & After \\
\hline $1 \mathrm{st}$ & 3.77 & 3.73 & -0.96 & 3.59 & 3.95 & 0.87 & 0.84 \\
\hline $3 r d$ & 6.40 & 6.34 & -0.95 & 6.15 & 6.66 & 0.93 & 0.79 \\
\hline 4th & 7.31 & 7.28 & -0.53 & 7.13 & 7.49 & 0.82 & 0.69 \\
\hline
\end{tabular}

\footnotetext{
a The standard deviations are used to establish the confidence intervals.
}

natural frequencies. This affected the vibration modes of the structure, resulting in a drop of the modal frequencies as well as a change of the frequency-temperature correlation after the occurrence of the seismic event (Table 7). However, the estimated frequency shift did not exceed the confidence limits established around each predicted value, meaning that only minor damage took place during the earthquake.

The temporal variation of the natural frequencies with respect to environmental and loading conditions is illustrated in Figs. 20 and 21. Given the low levels of ambient excitation and wind speed (cfr. Section 6.1), the variation of the modal frequencies is clearly imputable to the temperature effects and, to a certain extent, the humidity. Fig. 20 shows the evolution of the natural frequencies of the global modes with respect to the temperature together with the best trend lines and the coefficients of correlation $r$ and determination $R^{2}$. It can be clearly observed that all investigated frequencies show an almost linear increasing trend with rising temperature and vice versa. The lower modes exhibit a strong positive correlation, being $r$ and $R^{2}$ equal to 0.83 and 0.69 for mode 1 , and equal to 0.86 and 0.74 for mode 3 , respectively; whereas mode 4 is characterized by a frequency-temperature trend similar to mode 3 but less strong, as pointed out by the lower values of $r$ (0.74) and $R^{2}(0.55)$. It is noted that the positive correlation between modal frequencies and temperature is often observed in long-term studies of masonry structures [8-11] and can be 
(a) Temperture Effect on the First Mode

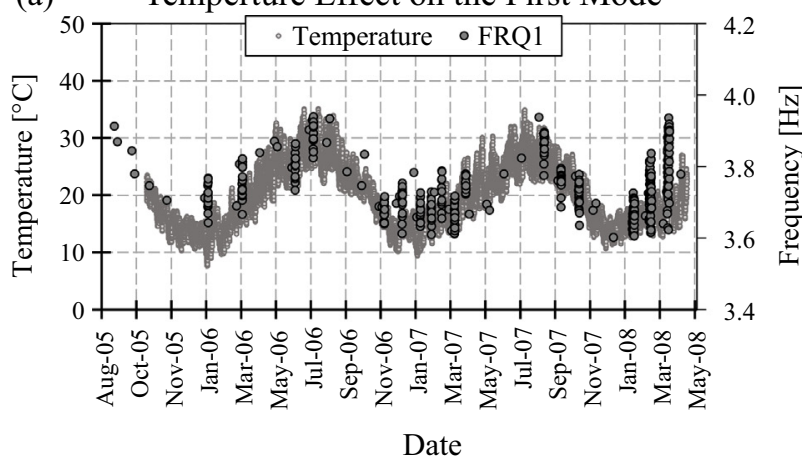

(b) Temperture Effect on the Third Mode

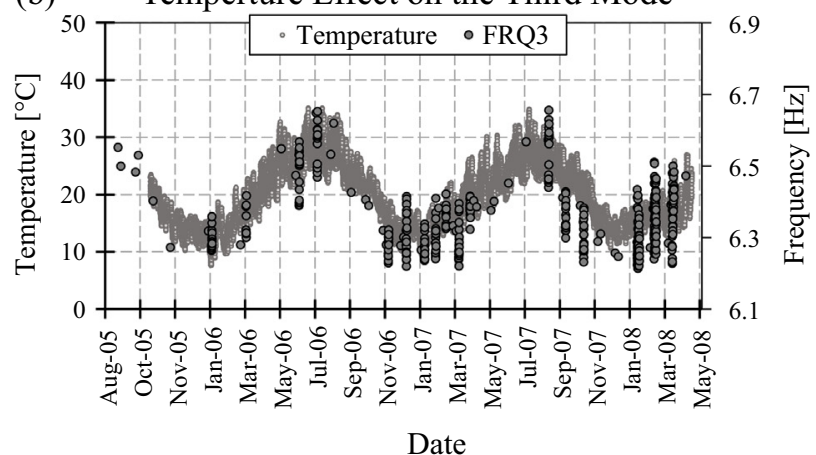

(c) Temperture Effect on the Fourth Mode

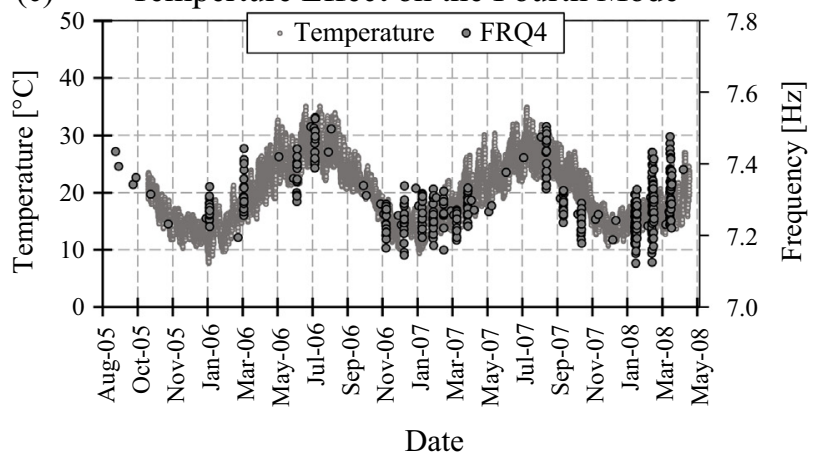

Mode 1

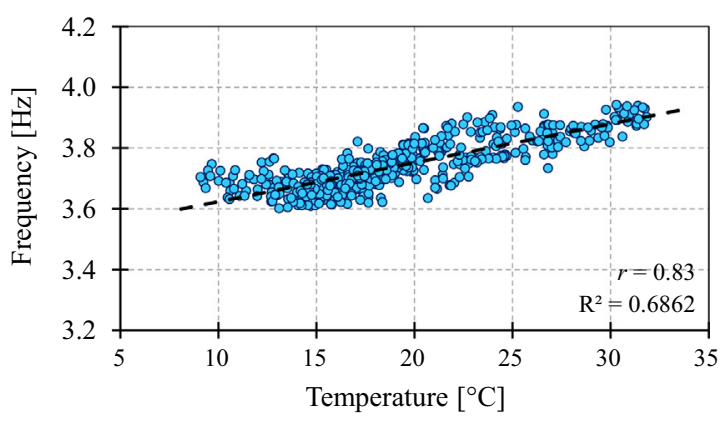

Mode 3

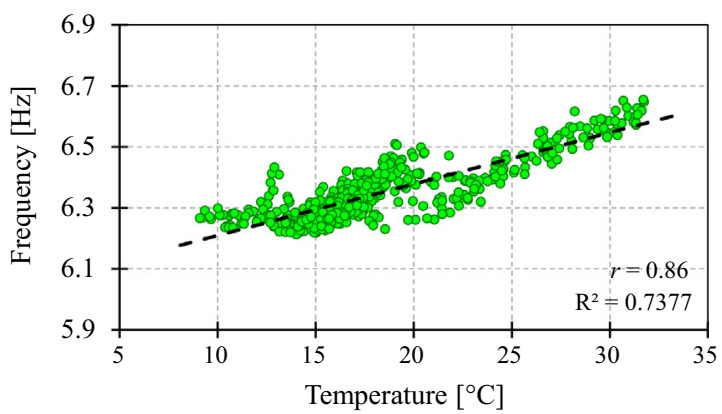

Mode 4

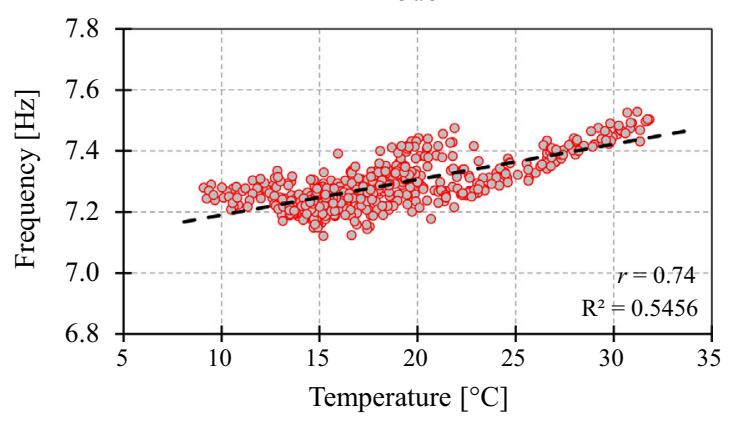

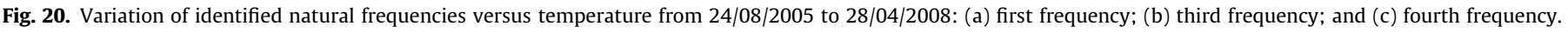

explained through the rise in stiffness induced by the thermal expansion of the materials with higher temperatures, lower moisture contents on the walls [7], and the consequent increase in frequency values. The plots relevant to modes 3 and 4 also highlight the considerable change in the frequency-temperature relationships triggered by the seismic event of February 2007. In order to analyse the possible influence of other environmental variables on the global modes of the church, the natural frequencies are plotted with respect to relative humidity, wind speed and ambient excitation (Fig. 21). The corresponding coefficients of correlation $(r)$ are given in Table 8. The plots show that the identified modal frequencies are characterized by a moderate linear correlation with the relative humidity, reading values of $r$ between $-0.40 \%$ and $-0.60 \%$. As the relative humidity does increase, the frequencies do decrease. This behaviour can be ascribed to the absorption of moisture by the masonry walls, responsible in turn for the increase of mass and the consequent decrease of frequency values [7], given their inverse relationship. Finally, it is stressed that no trend is found between modal frequencies and wind speed nor between modal frequencies and loading conditions (Fig. 21c and d).

\subsection{Final remarks}

The analysis of the monitoring data collected in the Church of Monastery of Jerónimos allows to conclude that the structural response of the system is controlled by the columns behaviour. The north column features rotation movements of greater amplitude with respect to the south column, but the displacements recorded hitherto do not compromise the bearing capacity of the church. In addition, it is noted that seasonal temperature and humidity variations significantly influence the structural response of the church, especially in terms of global modal behaviour. As far as wind and ambient noise are concerned, no impact on the static and dynamic response of the structure is found. Although the frequency shifts detected after the occurrence of the seismic event warned about the onset of possible endogenous phenomena linked 


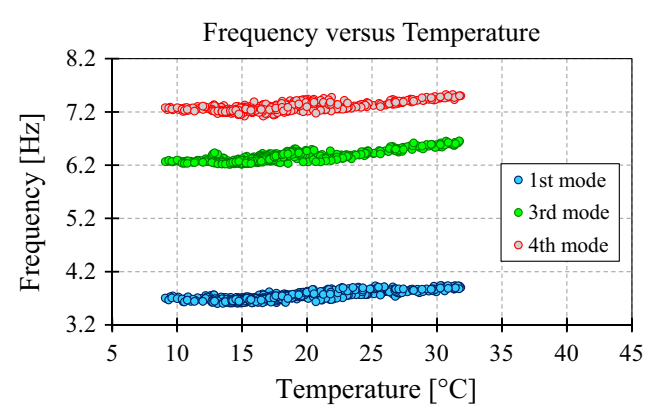

(a)

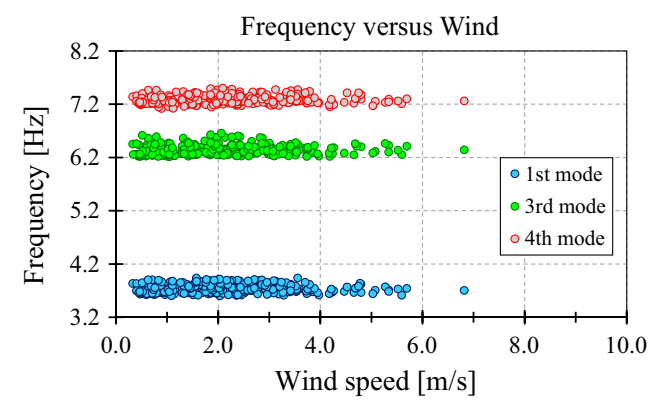

(c)

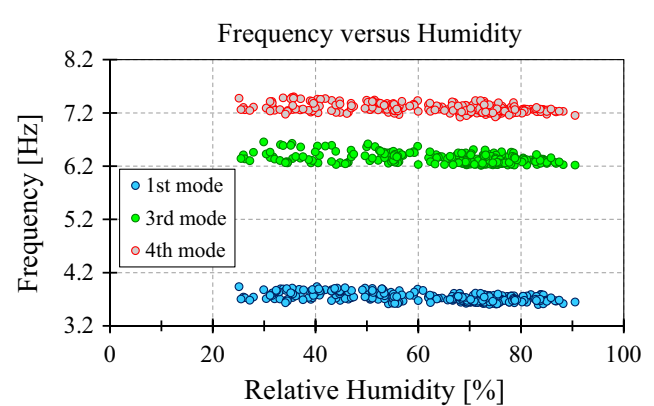

(b)

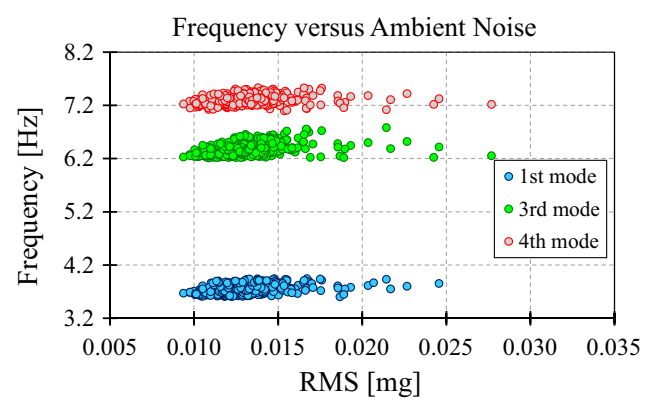

(d)

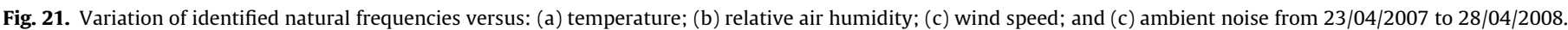

Table 8

Correlation between estimated modal frequencies and monitored environmental parameters.

\begin{tabular}{lllrr}
\hline Correlation [\%] & \multicolumn{4}{l}{ Environmental parameters } \\
\cline { 2 - 5 } & Temp. & Rel. Hum. & Wind & \multicolumn{1}{c}{ RMS } \\
\hline 1st Freq. & 0.83 & -0.56 & -0.06 & 0.14 \\
3rd Freq. & 0.86 & -0.41 & 0.07 & -0.04 \\
4th Freq. & 0.74 & -0.42 & 0.09 & -0.09 \\
\hline
\end{tabular}

to structural damage, the comparison with the confidence intervals defined for each mode allowed to rule out this hypothesis. Nevertheless, more data are needed to accurately model and predict the structural response of the church over time. Additional events are being collected for this purpose and the results will be presented in a future work.

\section{Conclusions}

The paper stresses the importance of a multidisciplinary approach for the structural analysis and the safety assessment of historical constructions. Anamnesis, diagnosis, therapy and control are the four key-steps to put into practice in order to guarantee a correct modus operandi for the preservation of architectural heritage. Appropriate tools for continuous structural health monitoring and advanced numerical modelling are indispensable to effectively analyse the structural behaviour of such nonconventional masonry systems and to identify possible anomalies and vulnerabilities which may compromise the structural performance over time. This has been demonstrated through the case study of the Church of Monastery of Jerónimos, in Lisbon. After an extensive experimental campaign carried out to characterize the geometrical and mechanical features of the church, a simplified FE model has been adopted for safety assessment purposes under conditions of gravity loading. The structural behaviour of the most critical part of the system has been analysed with focus on the bearing capacity of both north and south columns of the nave at different levels. This has allowed to understand how and to which extent the non-linear response of the supports affects the global behaviour of the structure. The finite element method has been used as a complementary analysis tool in combination with structural monitoring techniques for a complete evaluation of the state of preservation of the monument. The static and dynamic behaviours of the church have been thoroughly investigated along with the system's environmental variability. From the analyses carried out it is concluded that: (a) the temperature variation has a nonnegligible influence on the structural response of the church from both static and dynamic points of view and it is worth monitoring together with the relative humidity; (b) although the slenderness of the columns, the safety level of the church under conditions of vertical loads is good; (c) no urgent need for the adoption of specific remedial measures is found. It is worth mentioning that the information obtained from the continuous monitoring will be used to further validate the numerical model, especially in regard to the simulation of the effect of the environmental parameters.

\section{References}

[1] L.F. Ramos, Damage identification on masonry structures based on vibration signatures (Ph.D. thesis), University of Minho, Guimarães, Portugal, 2007.

[2] P.B. Lourenço, Recommendations for restoration of ancient buildings and the survival of a masonry chimney, Constr. Build. Mater. 20 (2006) 239-251.

[3] ICOMOS, Recommendations for the analysis, conservation and structural restoration of architectural heritage, 2001.

[4] G. Croci, The Conservation and Structural Restoration of Architectural Heritage, Computational Mechanics Publications, Southampton, 1998.

[5] B. Peeters, G. De Roeck, One-year monitoring of the Z24-Bridge: environmental effects versus damage events, Earthquake Eng. Struct. Dyn. 30 (2) (2001) 149 171.

[6] H. Sohn, Effects of environmental and operational variability on structural health monitoring, Philos. Trans. R. Soc. A 365 (1851) (2007) 539-560.

[7] L.F. Ramos, L. Marques, P.B. Lourenço, G. De Roeck, A. Campos-Costa, J.C.A. Roque, Monitoring historical masonry structures with operational modal analysis: two case studies, Mech. Syst. Signal Process. 24 (2010) 1291-1305.

[8] R. Cantieni, One-year monitoring of a historic bell tower, in: Proceedings of the 9th International Conference on Structural Dynamics, EURODYN 2014, 2014, pp. 1493-1500 (Porto, Portugal).

[9] A. Saisi, C. Gentile, M. Guidobaldi, Post-earthquake continuous dynamic monitoring of the Gabbia Tower in Mantua, Italy, Constr. Build. Mater. 81 (2015) 101-112. 
[10] A. Saisi, C. Gentile, Post-earthquake diagnostic investigation of a historic masonry tower, J. Cult. Heritage 16 (4) (2015) 602-609.

[11] F. Lorenzoni, F. Casarin, M. Caldon, K. Islami, C. Modena, Uncertainty quantification in structural health monitoring: applications on cultural heritage buildings, Mech. Syst. Signal Process. 66-67 (2016) 268-281.

[12] P.B. Lourenço, K.J. Krakowiak, F.M. Fernandes, L.F. Ramos, Failure analysis of Monastery of Jerónimos, Lisbon: how to learn from sophisticated numerical models, Eng. Fail. Anal. 14 (2007) 280-300.

[13] P.B. Lourenço, S. Mourão, Safety assessment of Monastery of Jerónimos, Lisbon, in: Proceedings of the 3rd International Seminar on Historical Constructions, University of Minho, Guimarães, Portugal, 2001, pp. 697-706.

[14] D.V. Oliveira, L.F. Ramos, P.B. Lourenco, J.C.A. Roque, Structural monitoring of the Monastery of Jerónimos, in: Proceeding of the International Conference on the 250th Anniversary of the 1755 Lisbon Earthquake, Lisbon, 2005, pp. 466-473.

[15] S. Genin, The nave vault of the Hieronymites Monastery Church in Lisbon, in: Proceedings of the Third International Seminar on Historical Constructions, University of Minho, Guimarães, 2001, pp. 293-302.

[16] J.C.A. Roque, Metodologia Integrada para Avaliação e Mitigação da Vulnerabilidade Sísmica das Construções Históricas em Alvenaria: A Igreja dos Jerónimos como Caso de Estudo (Ph.D. thesis), University of Minho, Guimarães, Portugal, 2010.

[17] R. Cantieni, Experimental methods used in system identification of civil engineering structures, in: Proceedings of the 1st International Operational Modal Analysis Conference, Copenhagen, 2005, pp. 249-260.

[18] R. Brincker, L. Zhang, P. Andersen, Modal identification of output-only systems using frequency domain decomposition, Smart Mater. Struct. 10 (3) (2001) 441-445.

[19] B. Peeters, G. De Roeck, Reference-based stochastic subspace identification for output-only modal analysis, Mech. Syst. Signal Process. 13 (6) (1999) 855-878.

[20] SVS, ARTeMIS Extractor Pro User's Manual, Release 5.4, Structural Vibration Solutions, Aalborg, Denmark, 2011.

[21] TNO Building and Construction Research, DIANA Finite Elements Analysis Release 9.1, 2005 (The Netherlands).

[22] MATLAB, User's Manual, Release 7.10.0, The Math Works, USA, 2010.

[23] E. Reynders, J. Houbrechts, G. De Roeck, Fully automated (operational) modal analysis, Mech. Syst. Signal Process. 29 (2012) 228-250. 